\title{
General and emotion-specific parenting styles as predictors of children's internalizing and externalizing behavior
}

Jessica W. Rupenthal

West Virginia University

Follow this and additional works at: https://researchrepository.wvu.edu/etd

\section{Recommended Citation}

Rupenthal, Jessica W., "General and emotion-specific parenting styles as predictors of children's internalizing and externalizing behavior" (2010). Graduate Theses, Dissertations, and Problem Reports. 4651.

https://researchrepository.wvu.edu/etd/4651

This Thesis is protected by copyright and/or related rights. It has been brought to you by the The Research Repository @ WVU with permission from the rights-holder(s). You are free to use this Thesis in any way that is permitted by the copyright and related rights legislation that applies to your use. For other uses you must obtain permission from the rights-holder(s) directly, unless additional rights are indicated by a Creative Commons license in the record and/ or on the work itself. This Thesis has been accepted for inclusion in WVU Graduate Theses, Dissertations, and Problem Reports collection by an authorized administrator of The Research Repository @ WVU. For more information, please contact researchrepository@mail.wvu.edu. 
GENERAL AND EMOTION-SPECIFIC PARENTING STYLES AS PREDICTORS OF CHILDREN'S INTERNALIZING AND EXTERNALIZING BEHAVIOR

\author{
Jessica W. Rupenthal
}

Thesis submitted to the College of Human Resources and Education at West Virginia University

in partial fulfillment of the requirements for the degree of

\author{
Master of Arts \\ In Educational Psychology \\ With an emphasis in Child Development and Family Studies
}

\author{
Amy E. Root, Ph.D., Committee Chairperson \\ Kristin Moilanen, Ph.D., Member \\ Amy Gentzler, Ph.D., Member \\ Department of Technology, Learning, and Culture
}

Morgantown, West Virginia

2010

Copyright 2010 Jessica W. Rupenthal 


\begin{abstract}
General and Emotion-specific Parenting Styles as Predictors of Children's Internalizing and Externalizing Behavior
\end{abstract}

Jessica W. Rupenthal

The purpose of this study was to investigate the relation between general parenting practices (e.g., authoritative and authoritarian) and emotion-specific parenting practices (supportive and non-supportive). In addition, a second goal of this study was to examine the manner which general parenting practices and emotion-specific parenting practices collectively contribute to children's displays of fear/anxiety and hostility/aggression. Data were gathered from 27 mothers (mean age $=34$ years) and their preschool-aged children (14 boys, 13 girls; mean age $=3.5$ years) in Morgantown, West Virginia. The majority $(92 \%)$ of mothers were White (4\% Black, 4\% Bi-racial). Mothers completed a series of questionnaires. In order to assess general parenting typologies and emotion-specific parenting practices, mothers completed the Parenting Practices Questionnaire (PPQ; Robinson, Mandleco, Frost, Olsen, \& Hart, 1995) and the Coping with Children's Negative Emotions Scale (CCNES; Fabes, Poulin, Eisenberg, Madden-Derdich, 2002). Mothers also rated their children's hostility/aggression and fear/anxiety via the Preschool Behavior Questionnaire (Behar \& Stringfield, 1974). Bivariate correlation analyses were conducted and it was determined that authoritative parenting was significantly and positively related to supportive emotion socialization strategies in response to children's anger and fear. In addition, authoritarian parenting was significantly and positively related to nonsupportive fear. A series of multiple regressions were also conducted and indicated that authoritarian parenting was a significant (negative) main effect predictor of fear/anxiety. Finally, the interaction between authoritarian parenting and non-supportive-anger was predictive of fear/anxiety at the trend level. The implications of examining general and emotion specific parenting practices as contributors to children's social and emotional development are discussed. 


\section{Acknowledgements}

First and foremost I would like to thank my wonderful family for their unwavering support throughout my college career. When times were tough and I was on the brink of breaking down, I could always count of each of you for your kind words and positive encouragement. I especially would like to offer thanks to my mother, who, throughout all of the ups and downs has been my rock. Mom, I always have been able to count on you. Your love, support and belief in my abilities (even when I didn't believe in myself) is what has helped push me to achieve what once seemed so far out of reach. You're an amazing mother and a wonderful friend. I truly believe that I owe part of this degree to you. Throughout this process the meaning of family really hit home. Although the focus of my thesis was in regards to preschool-aged children, I believe that the same processes still hold true as an adult, and for that I am very lucky to have such a warm, supportive, and nurturing family (Baumrind and Fabes would be agree).

Next, I want to thank each of my committee members, Dr. Amy Root, Dr. Kristin Moilanen, and Dr. Amy Gentzler for your guidance during this process. Your feedback and support is what helped make this document possible. The knowledge I have gained while working with each of you is invaluable. Amy, you have been an amazing teacher, mentor, and friend and I am honored to have had the opportunity to work so closely with you during the past year. Your encouragement and guidance has meant the world to me. You helped me view things from a different perspective and really fueled my interest in the study of emotion socialization. Words cannot express how thankful I am for all that you have done, and all that you have helped me to achieve.

In addition, I would like to thank the Child Development and Family Studies faculty members and staff. It is certain that I have learned so much in the realm of child development 
from each of you. Last, but not least, I would like to thank my friends and classmates for their support. Sharing the experience of graduate school has helped us to develop a unique bond that I believe will last a lifetime. 


\section{TABLE OF CONTENTS}

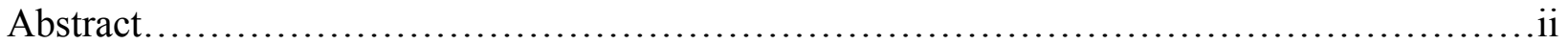

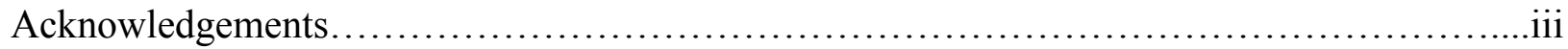

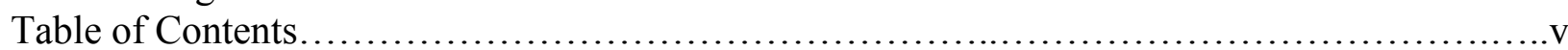

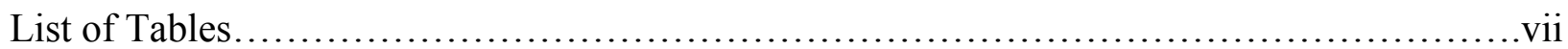

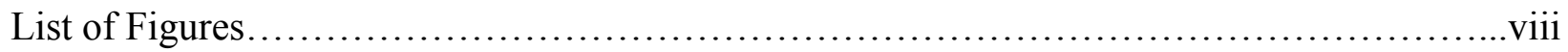

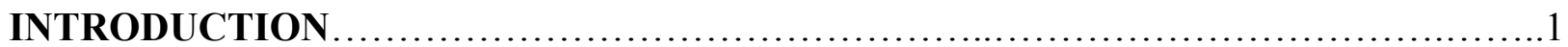

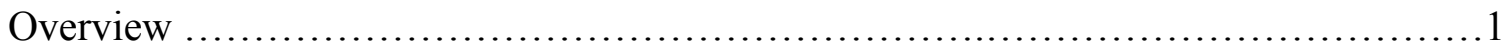

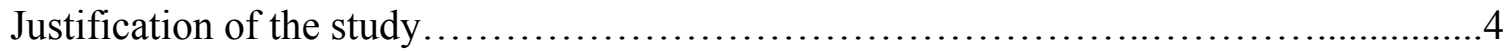

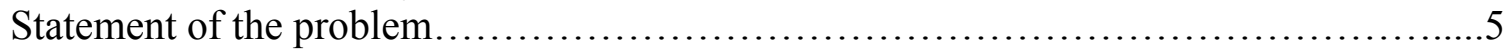

CHAPTER 1: Review of Literature....................................................6

General Parenting Styles............................................6

Parenting Styles Associated with Child Behavior.......................8

Emotion Specific Parenting Practices................................. 16

Supportive vs. Non-supportive Reactions.........................17

Parental Reactions to Children's Emotions and Children's Emotional

Competence.................................................... 19

Collective Examination of Global and Emotion-specific Parenting

Practices......................................................... 37

The Current Study.................................................40

Hypotheses.................................................40

CHAPTER 2: Methods.....................................................................43

Participants.......................................................43

Procedure......................................................... 43

Measures.........................................................44

Demographics........................................44

Parenting Practices Questionnaire..........................44

The Coping with Children's Negative Emotions Scale...........44

Pre-School Children's Social Behaviors Questionnaire -

Parent's..................................................45

Analytic Strategy..............................................46

CHAPTER 3: Results...........................................................................47

CHAPTER 4: Discussion..............................................................50

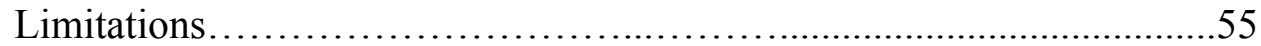

Future Directions................................................. 57

Conclusion....................................................60

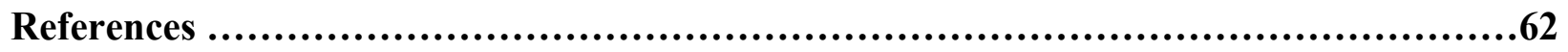

Appendices............................................................................74 
Appendix A: Demographic Information...................................................74

Appendix B: Parenting Practices Questionnaire...........................................78

Appendix C: Coping with Children's Negative Emotions Scale.............................82

Appendix D: Pre-School Children's Social Behaviors Questionnaire.........................87 


\section{List of Tables}

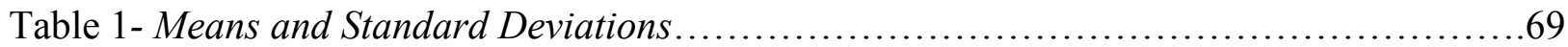

Table 2-Correlations................................................................ 70

Table 3- Regression Analyses - CCNES Anger.......................................... 71

Table 4- Regression Analyses- CCNES Fear..........................................72 


\section{List of Figures}

Figure 1- Fear/Anxiety as a Function of Authoritarian Parenting as Levels of Non-supportive

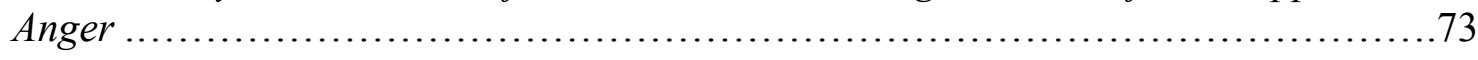




\section{Introduction}

\section{Overview}

For many years, researchers have sought to understand the development of social and emotional competence during the preschool years. Two bodies of research have resulted from this interest in the role of parents in the development of children's socio-emotional competence. Beyond parenting specific to emotional development, it is relatively well-accepted that parents who utilize warm, comforting parenting strategies in which children's individual independence is stressed (also referred to as authoritative parenting) have children who demonstrate superior selfregulatory strategies, appropriate understanding of emotion, and in turn, are able to distinguish emotion across a variety of social contexts (Baumrind, 1971). In contrast, the opposite holds true for children raised by parents who demonstrate an authoritarian or permissive approach to parenting. Authoritarian parents are much less nurturing than authoritative parents, and tend to strongly value the role of discipline in the parent-child relationship. Children growing up in authoritarian homes are expected to obey parental requests without questioning authority, thus eliminating the use of open, expressive communication between the parent and child. On the contrary, permissive parents tend to take a laissez-faire approach to parenting. This type of parenting style aims to avoid conflict with children at all costs, even if it means acting as their children's friend rather than their parent. A consistent lack of discipline is also apparent when examining permissive parenting styles. While guidelines or rules may be established, parents rarely discipline their children when they cross set boundaries. Instead, permissive parents often rely on methods of bribery when attempting to achieve a desired outcome from their children. Hence, authoritarian and permissive parenting styles have been found to lead to less adaptive 
child outcomes such as low levels of academic achievement, childhood aggression, and low levels of appropriate emotion coping (Baumrind, 1971).

Researchers have moved beyond assessments of general parenting practices, and have begun to examine emotion specific parenting practices as they relate to children's social and emotional development, or emotion socialization. Emotion socialization practices have typically been characterized as supportive or unsupportive. Parents who take a supportive approach to emotion-specific parenting styles are those who are emotion-focused, problem-focused, and those who utilize expressive encouragement (Fabes, Poulin, Eisenberg, \& Madden-Derdich, 2002). Emotion-focused parenting can be described as a parenting style in which the parental aim is to facilitate children's happiness and emotional well-being. Similarly, problem-focused parenting consists of supportive parenting strategies which aim to assist children when dealing with situations that are emotionally distressing. Finally, a third supportive emotion-specific parenting practice is expressive encouragement. Expressive encouragement is based on parental acceptance of children's displays of negative emotions. In contrast, non-supportive reactions to emotion-specific parenting can be labeled as punitive reactions, and minimization reactions. A punitive reaction to children's emotion is an emotion-specific parenting practice in which children are punished (either verbally or physically) in an attempt to have power over their displays of emotion (Fabes et al., 2002). A minimization reaction can be described as parental disregard or the devaluing of children's reactions to emotion eliciting situations or problems (Fabes et al., 2002).

Separate from the associations between general parenting style and related child outcomes, the manner in which parents react to emotions elicited from children are also found to influence child behavior outcomes. Fabes et al. (2002) even go as far to suggest that the parents 
may elicit varying responses from children based on the specificity or the nature of the expressed emotion the child exhibits and the manner in which they respond to it. For example, parents may respond to emotions of a positive nature differently than those of a negative nature when they are expressed by children, thus altering the parent's response to the said emotional display.

Likewise, when examining emotion-specific parenting practices researchers believe that parents who are unsupportive, when compared to supportive parenting approaches, will have children who have difficulty regulating emotion, and often do not demonstrate socially appropriate means when expressing emotionality (Fabes et al., 2002).

Although the examination of specific parenting practices has allowed for more precise assessment of how parents impact children's development, not all believe that children's socioemotional development can be understood by studying just one developmental trajectory. Empirical research separately examining the manner in which general parenting styles or emotion specific socialization strategies influence child behavior outcomes have been examined, however the need to further examine the way general parenting styles and emotion specific parenting practices collectively affect child behaviors are evident. Thus, it is believed that both emotion-specific socialization, as well as typical typologies of parenting style (e.g., authoritative) must be examined together in order to truly understand the impact of parenting (e.g., O'Neal \& Magai, 2005). Although many believe that this is the best way to examine developmental outcomes, little has been done to examine the affects of both global and specific parenting practices on children's social and emotional development. Once researchers are able to gain understanding into the development of varying child psychopathologies based on parenting type, necessary prevention and intervention measures can be developed based on both parenting style, and reactions to specific emotional encounters. 
According to researchers in the field of developmental psychology, the prime time to conduct research on children's social and emotional development is during the preschool years (Denham, 1998). During this age range, children's cognitive abilities are beginning to flourish, making this an opportune time to study children's emotional competencies (Denham, 1998). During early childhood, parents serve as primary socialization agents in regard to children's social and emotional development. During early childhood children are influenced and affected by the manner in which their parents model emotion through both discussions of emotional situations as well as parental emotional expressiveness. Similarly, the way parents respond to their children's displays of emotion has also been found to influence children's overall understanding of emotion and emotion regulatory attempts (Denham, 1998). Influences in the domain of children's emotion socialization during the early childhood years have also been associated with children's latter socio-emotional development and behavioral functioning such as variations in emotional competencies, regulatory capabilities, and subsequent internalizing and externalizing behaviors. Thus, much of the research conducted in the realm of emotional development in young children takes place during the preschool years.

\section{Justification for the Study}

Much of the research conducted in the parenting literature has separately spotlighted Baumrind's general parenting styles and the way they affect child behavior outcomes, or emotion-specific parenting practices and various child behavior outcomes. Studies separately examining the manner in which general parenting styles or emotion specific socialization strategies influence child behavior outcomes are few; thus there is a need to further examine these aspects of how parenting collectively affects the development of child behaviors. This is essential since recent evidence from the emotions socialization literature has indicated that 
examining both global and specific emotion socialization strategies provides a powerful prediction of children's subsequent behavior (O'Neal \& Magai, 2005); thus, it seems likely that the examination of general parenting style and emotion socialization beliefs will be particularly useful in predicting socio-emotional development in preschool-aged children.

\section{Statement of the Problem}

The purpose of this study is to investigate the relation between general parenting style (i.e. authoritative and authoritarian), and emotion-specific parenting practices (supportive and non-supportive). Additionally, a second purpose of this study is to examine the manner in which general parenting styles and emotion-specific parenting practices collectively contribute to and predict child behavior outcomes, specifically, internalizing and externalizing child behaviors. While researchers agree that both global parenting styles and emotion-specific parenting styles are important areas to examine (O'Neal \& Magai, 2005; Fabes et al., 2002), little has been done to examine the combination of both processes and the impact they may have on children's social and emotional developmental outcomes. 


\section{Chapter 1}

\section{Review of Literature}

For many years, researchers have sought to understand the development of emotion competence during the preschool years through both empirical and descriptive research studies (Baumrind, 1971; Baumrind \& Black, 1967; Domitrovich \& Bierman, 2001; Denham, 1998). Previous research has determined that parents play a crucial role in the development of children's emotion. Studies separately examining the manner in which general parenting styles or emotion specific socialization strategies influence child behavior outcomes have been examined, however, the need to further investigate the way general parenting styles and emotion specific parenting practices collectively affect child behaviors are evident throughout the literature (e.g., O’Neal \& Magai, 2005). Through the examination of multiple pathways of influence, more accurate predictions of child outcomes regarding emotion socialization can be established. Throughout this thesis, both of these viewpoints will be addressed. Specifically, I will begin by reviewing studies examining authoritative, authoritarian, and permissive parenting styles. Next, I will identify, examine, and review studies of emotion specific parenting practices.

\section{General Parenting Styles}

According to Baumrind (1971) parenting practices can be broken down into three general styles, which are authoritative, authoritarian, and permissive. Parents who practice the authoritative parenting technique can be identified as those who aim to enhance their children's environmental well-being, promote autonomy separate from the parent-child relationship while playing an active role in their children's upbringing (Baumrind, 1971). Authoritative parents also actively illustrate tenderness and warmth toward their offspring, and aim to ensure that their children respect and comprehend the reason for rules and understand the repercussions of their 
wrongdoings (Baumrind, 1971). This type of parenting style also consists of open, expressive communication between parent and child. Although the child is expected to communicate with their mother and father regarding their needs, feelings, and troubles, the parent also shares the role of communicating their concerns, interests, and expectations (Baumrind, 1971).

When compared to authoritative parents, authoritarian parents, are much less lenient (Baumrind, 1971). Parents categorized as authoritarian can be described as demanding, rigid, and controlling. Authoritarian parents tend to follow a strict system of parenting and have even been compared to 'military style parents'. It is not uncommon for this type of parent to use physical punishment such as spankings and slaps when the child behaves poorly. In addition, a lack of communication exists between authoritarian parents and their children. Children are told, rather than asked, to complete tasks without any sort of clear direction or explanation, and when the child's performance doesn't meet the parent's expectations, they are scolded and punished in an effort to enhance their performance (Baumrind, 1971).

Quite different than the previously mentioned parenting styles, permissive parents demonstrate a 'laissez-faire' approach to parenting, in which clear-set boundaries are not established between the parent and child. Permissive parents also illustrate a hands-off approach when it comes to discipline, and tend to accept the child's behavior (good or bad) without regard to consequence. In an effort to achieve a desired behavior from the child, permissive parents often turn to bribery. When the child behaves in a way that warrants a form of discipline, these parents typically do not follow through with the threatened punishment (Baumrind, 1971). One reason for the lack of discipline demonstrated by permissive parents is the parental fear that the child will dislike their parents after punishment is delivered (Baumrind, 1971). Rather than punish their children for bad behavior, permissive parents choose not to get involved and as an 
alternative, ignore misbehaviors altogether.

\section{Parenting Styles Associated with Child Behavior}

Support for a relation between parenting practices and child outcomes were also illustrated in two separate studies conducted by Baumrind and Black (1967). In this series of studies, the relation between parenting techniques and child behavior outcomes were examined. The objective of the first study was to determine if children who were seen as self-assured, outgoing, and well-behaved were reared differently than those who were socially withdrawn and those children who lacked self-control. Thirty-two children and their families participated in the study, which consisted of observations in the school and home settings. During home visits, a psychologist would visit the home shortly before evening meal time, and collect data up until the children have been put to bed for the evening.

Preschool observations were used to assess children's behaviors, including: overanxious behavior, children's general disposition, as well as interpersonal characteristics such as "selfcontrol, perseverance, self-reliance, self-assertiveness, friendliness, and cooperativeness" (Baumrind \& Black, 1967, p. 293). During the home sessions psychologists coded the behavior of parents and children, paying special attention to family members' (both parents and children) attempts to modify the behaviors of another. Specifically, families were observed using the Home Visit Sequence Analysis (HVSA). The HVSA measured the following parenting dimensions: warmth, consistent discipline, maturity demands, restrictiveness, punitiveness, encourages independent contacts, socialization demands, and strictness concerning orderliness.

These assessments were used to examine relations between parenting style and child behavior, and they reported that children who were assertive and well behaved in the classroom were found to have parents who were controlling, yet communicative and loving. On the other 
hand, shy, or socially inhibited children were found to have parents who were very strict and rigid as well as emotionally disconnected (Baumrind \& Black, 1967). Lastly, children of the final group (children lacking self-control) had parents who were found to be "non-controlling, nondemanding, and relatively warm" (Baumrind \& Black, 1967, p. 292).

Baumrind and Black (1967) conducted a second study in an effort to substantiate their previous research regarding parenting attitudes and child outcomes. Measuring instruments from study one and two were consistent (Home Visit Sequence Analysis). In this study, 95 preschoolers and their families served as participants. Baumrind and Black (1967) reported that parenting characterized as encouraging autonomy and power balanced was associated with competent child behaviors. For instance, parental consistent discipline was positively associated with confidence, assertiveness and imagination in males, and independence and friendliness among girls (Baumrind \& Black, 1967). For both males and females, paternal consistent discipline was positively related to developmentally appropriate behaviors in children (Baumrind \& Black, 1967). When examining the variable maturity demands (e.g., helped their mother perform household tasks), a positive correlation regarding confidence, assertiveness, and independence for boys was established (Baumrind \& Black, 1967). Conversely, parenting characterized by punitive behaviors was positively associated with incompetent social behaviors including deviance as well as behaviors characterized as "unlikable" (Baumrind \& Black, 1967). Surprisingly, parental warmth was not found to be a significant predictor when examining competent child behavior (Baumrind \& Black, 1967). Consistent with the initial results, Baumrind and Black (1967) further confirmed that parents who were consistent and caring, yet firm raised children who were competent, self-controlled, assertive and independent.

Stemming from this initial research (e.g., Baumrind \& Black, 1967), Baumrind (1971) 
conducted an additional study in an effort to replicate and build on previous studies of this kind. Baumrind (1971) determined that child behaviors associated with particular parenting styles differ in many ways. It was found that sons reared in authoritarian households displayed signs of aggressive behavior while daughters were seen as "suggestible, yet, socially conforming" (Baumrind, 1971, p. 47). Moreover, sons and daughters raised in authoritarian homes were found to demonstrate low levels of independence and social responsibility (Baumrind, 1971), and both sexes shared a lack of interest in future goals. Thus it appears that authoritarian parenting is associated with less adaptive outcomes in children such as low levels of self-esteem and childhood aggression.

Moreover, Baumrind (1971) reported that preschool-aged sons of authoritative parents were observed to be more forthcoming (helpful), accommodating, and less dominant in behaviors over a 3-month period when compared to preschool-aged girls of authoritative parents. However, according to Baumrind (1971), preschool-aged girls raised by authoritative parents as indicated in Baumrind's study were found to be more dominant than males. Both genders were found to be achievement-oriented and scored much higher in areas of social responsibility than children reared by authoritarian parents. In sum, preschool-aged children of authoritative parents are the most likely to develop sufficiently (i.e. demonstrate prosocial behaviors, dedicate attention to academic achievement, and behave in a socially responsible manner) (Baumrind, 1971).

Baumrind (1971) also reported, although not significant, daughters of permissive parents were observed as more obedient and socially responsible, while sons were found as resistant as well as showing lower regard for achievement than those raised in authoritarian or authoritative households. When compared to children of authoritative parents, permissive sons had low social 
responsibility scores (Baumrind, 1971). Moreover, daughters of permissive parents were also found to be less independent when compared to daughters of authoritative parents, while males were significantly less independent than those reared by authoritative parents (Baumrind, 1971). Hence, children raised by permissive parents were likely exhibit undesirable child outcomes such as lack of responsibility, self-control, and motivation.

Based on the notion that general parenting styles as described by Baumrind $(1967,1971)$ are associated with subsequent child outcomes, it is crucial that these influences be examined in further capacities. By taking a deeper look into the relations between general parenting styles and associated child outcomes researchers could use this information to generalize across populations, and provide information to parents that could potentially help them to interact and raise their children in a manner that will be socially and emotionally beneficial in the future. These classic studies also provided support for future research, including examining these processes beyond the preschool years. For instance, Lamborn, Mounts, Steinberg and Dornbusch (1991) examined how variations of parental warmth, indulgence, and restrictiveness affect adolescent behavioral outcomes.

Lamborn et al. (1991) believed that children from authoritative households would show the most socio-emotional success, assuming that the opposite would hold true for children raised by those who took a neglectful approach to parenting. They also believed that when academic scores and problem behaviors were measured, children whose parents were authoritarian would score higher in these domains than the children raised in indulgent families (Lamborn et al., 1991). Lastly, Lamborn et al. (1991) hypothesized that children raised by authoritarian parents would score much lower in the domains of internalized distress and psychosocial development when comparing children reared in indulgent homes. 
Participants in this study included 4,100 adolescents and their families. The adolescents rated their family members based on their levels of acceptance/involvement and strictness via a self-report questionnaires; family members were then placed into four separate categories based on these reports: authoritative, authoritarian, indulgent, and neglectful parenting styles. In addition, adolescents' adjustment was assessed on four separate outcomes including psychosocial development, school achievement, internalized stress, and problem behavior. Data was collected based on questionnaire data. First, adolescents completed one questionnaire about their mother's parenting practices and one questionnaire about their father's parenting practices, and ratings were then averaged across mothers and fathers.

Next, adolescents completed questionnaires about their psychosocial development, school achievement, internalized stress, and problem behavior. Psychosocial development was measured via adolescent report of social competence via Adolescent Self-Perception Profile (Harter, 1982) and the work orientation and self-reliance scales from Greenberger's Psychosocial Maturity Inventory (Greenberger, Josselson, Knerr, \& Knerr, 1974). School achievement was assessed via grade point average, academic competence from the Harter scale (Harter, 1982), and adolescent's orientation towards school (items derived from Wehlage, Rutter, Smith, Lesko, \& Fernandez, 1989). Adolescents' internalized stress was assessed via the somatic symptoms and psychological symptoms subscales from the Depression Scale of the Center for Epidemiologic Studies (Radloff, 1977). Finally, adolescent problem behavior was assessed via measures of drug and alcohol use, school misconduct, and delinquency.

Multivariate analysis of variance tests were used to examine the how the four parenting groups differed on assessments of adolescent adjustment. Lamborn et al. (1991) reported that children who were raised by authoritative parents reported higher levels of overall 
socioemotional stability. For example, children of authoritarian, indulgent, and neglectful parents, when compared to children raised in authoritative households, scored significantly lower in respect to academic competence, psychosocial development, and a great deal higher in regard to problem behaviors (Lamborn et al., 1991). It was also established that children raised in neglectful homes demonstrated greater levels of internalizing, somatic, and psychological symptoms than children from either indulgent or authoritarian families (Lamborn et al., 1991). It is important to point out that while children reared in authoritative households excelled in most competence domains, no significant factors separated them from children of authoritarian households in regard to substance abuse, grade point average, or delinquency (Lamborn et al., 1991). Hence, children reared by authoritarian parents were not more likely than children reared in authoritative households to abuse substances, differ in academics, or engage in adolescent delinquency. In addition, no significant differences were found regarding children raised in authoritative or indulgent households when evaluating social competence, delinquency or selfreliance (Lamborn et al., 1991).

Lamborn et al. (1991) determined that adolescents raised in neglectful homes were found to score lower when comparing social and emotional competencies, thus supporting their previous hypothesis. It was also found that children of neglectful families were worse off in each of the measured domains when compared to children of authoritative households. However, no significant differences were found when children of neglectful families were compared to adolescents in authoritarian households (Lamborn et al., 1991). Lastly, similarities were found between children of neglectful and indulgent families regarding measures of behavioral/somatic difficulties, engagement in education, and self-reliance (Lamborn et al., 1991).

Contradictory to their previous hypothesis stating that children from authoritarian 
families would score more positively in domains of psychosocial development and internalized distress when compared to children of indulgent families, Lamborn et al.'s (1991) hypothesis was not supported. Instead, Lamborn et al. (1991) found that children from authoritarian and indulgent households had many similarities in their strengths and weaknesses. For instance, while children reared in authoritarian households had less behavioral difficulties in school and were more accustomed to the idea of school in general, children raised in indulgent households were identified as having higher levels of academic competence (Lamborn et al., 1991).

In general, the study conducted by Lamborn et al. (1991) demonstrates differences in adolescent outcomes dependent on the manner in which children are raised. Whether children are brought up in authoritarian, authoritative, indulgent or neglectful households it is seems that parenting practices have a direct impact on children's socio-emotional competence and their emotional stability. Differences in the way that parents interact or raise them may in turn help or hinder children's development in a variety of domains, and the findings indentified by Lamborn and colleagues (1991) help to support this claim. Results provided by this study highlight the importance of examining the relationship of parenting on child behavior outcomes. While the findings provided by Lamborn et al. (1991) highlighted these associations during adolescence, it is also important to examine how parenting affects development in the early childhood years.

Domitrovich and Bierman (2001) examined the association between parenting practices and children's social adjustment in a sample of elementary-aged children. In order to determine parenting styles, mothers, fathers, and their children completed questionnaires about positive and negative parenting techniques; further, peers rated children's social behaviors and children's problem-solving skills were assessed via hypothetical social situations. Domitrovich and Bierman (2001) hypothesized that a relations would emerge between parent-ratings of parenting 
practices and indices of children's socio-emotional development; further they expected that children's perceptions of their parents' parenting practices would be related to peer and selfratings of social behavior

These hypotheses were tested in a sample of 140 -fourth grade students and their parents. Questionnaires were completed in the home; mothers completed an inventory of parenting about their own parenting behavior and about the parenting behavior of their spouse. This inventory yielded two scales: warm support and hostile control; questions were derived from Love and Kaswan (1974); Schaefer (1965); and Schludermann and Schludermann (1970). Children completed an adapted Parenting Practices Rating Scale to assess their perceptions of warm support and hostile control from their mothers, fathers, and friends. Children also completed an assessment of their social problem solving skills (Dodge, Bates, \& Pettit, 1990) and answered questions about his/her loneliness in the peer group (Asher \& Wheeler, 1985) and victimization. Finally, after the home visits, children's classmates were asked to complete sociometric ratings, which yielded assessments of popularity and victimization.

Data were analyzed using hierarchical regression analyses. First, Domitrovich and Bierman (2001) reported that maternal reports of parenting practices were related to children's perceptions of parenting practices and children's perceptions of their relationships with their friends. Specifically, it appears that children's ratings of maternal support were predicted by maternal ratings of warmth and support and children's perceptions of support from a friend. Moreover, Domitrovich and Bierman (2001) reported a positive relation between supportive parenting practices (obtained via maternal self-report) and children's ratings of prosocial behavior on the social problem solving skills interview. In addition, although not significant, maternal supportive behavior was negatively related to children's ratings of aggression during 
the social problem-solving skills interview. Further, children who reported low occurrences of loneliness and peer victimization at school were found to have parents who were observed as warm and supportive (Domitrovich \& Bierman, 2001). A significant association was also found between children whose parents were non-supportive and hostile, and peer victimization and loneliness at school. Through examining children's problem-solving techniques, it was determined that the manner in which children deal with conflict was also predicted by maternal and paternal parenting techniques. Therefore, it appears that parents serve as a model to which children refer to when interacting with their peers. For instance, it was found that parents viewed as warm and supportive had children who were more inclined to use prosocial problem solving skills, in turn resulting in low levels of peer dislike.

Hence, it is clear that parenting practices are associated with children's social development, thus supporting Domitrovich and Bierman's (2001) original hypotheses. Parenting techniques not only affected the way children perceive their parents, but it also influences the way children view their social surroundings. Children rely on personal experiences with family members as a resource to help them comprehend both the relationships they have with peers, as well as the relationships they observe their peers have with others. Although the impact may vary, it can be determined that mothers' and fathers' choices of parenting practices and they way children perceive their parents both have influence over children's overall social adjustment.

\section{Emotion Specific Parenting Practices}

Previous research conducted by Baumrind (1967; Baumrind \& Black, 1971) has provided researchers with valuable insight into the roles parents play in children's development. However, subsequent research has somewhat shifted focus to more specific aspects of parenting, such as the socialization of emotion. Indeed, the approach parents use when responding to their 
children's displays of emotions (emotion socialization), as well as the manner in which parents model and discuss emotion has both a direct and an indirect effect on children's social and emotional development. In the most recent review of the literature on the socialization of emotion, Eisenberg, Cumberland and Spinrad (1998) detailed issues pertaining to parental direct socialization of children's emotion. Direct socialization includes discussion of emotion and responses to children's displays of emotions. Given one of the foci of the current study was to examine parental reactions to children's emotions, I will only review the literature on parents' reactions to children's emotions.

\section{Supportive vs. non-supportive reactions.}

The literature on the socialization of emotion has indicated that parents respond to emotions in either a supportive or non-supportive fashion. In a study produced by Gottman, Katz and Hooven (1997) in which parental awareness of emotion and child outcomes were examined, a form of supportive reaction labeled emotion coaching was described. The term emotion coaching can be described as verbal communication between children and authority figures in which emotion is elaborately discussed in an effort to increase children's understanding of appropriate displays of emotion, as well as teach techniques to self-regulate during intense or unpleasant circumstances (Gottman et al., 1997). Such skills as identified by Gottman and colleagues (1997) have been shown to encourage behaviors characterized as socially appropriate, and in turn, reduce problem behaviors. For instance, in one study, children whose parents utilized emotion coaching in the home were found to be more effective in their self-regulatory efforts (Gottman et al., 1997). In addition, these children were superior in their ability to transfer their self-regulatory capabilities to social situations outside the home environment (Gottman et al., 1997). 
One aspect of emotion coaching is responding to children's emotions in an effective manner. Indeed, parental reactions to their children's emotions are perhaps one of the most important means by which individuals contribute to children's overall positive emotional development (Denham, 1998). Specifically, it seems that when parents and adults take a nonsupportive approach to children's displays of emotions have children who exhibit more social and emotional difficulties, whereas when parents respond to children's emotions in a more supportive fashion children generally grow into more emotionally and socially competent individuals (e.g., Denham, 1998). Therefore, it seems that parents can help or hinder their children's development simply by the manner in which they react to their children's emotional displays.

Associations found between supportive and unsupportive reactions to children's emotions and children's overall emotional development can be described in a number of ways. First, situations in which parents respond in a supportive manner to their children's displays of both positive and negative emotions are related to positive overall emotional development. This process can be explained based on the type of reinforcement a child is receives in these situations. When children are encouraged to be emotionally expressive and discuss their emotions, they are being reinforced through parental support. In other words, parents are communicating to their child that it is okay to express emotions (via reassurance) and this is how you can manage those feelings (via discussion).

Indeed, children use parents as a reference to determine which emotions are socially acceptable, and how to appropriately express and manage those emotions. Likewise, parents who respond to their children in an unsupportive manner following overt emotional expression are likely communicating that the expression of affect is unacceptable, but also they likely are not 
communicating to their child how to effectively express or regulate affect.

\section{Parental Reactions to Children's Emotions and Children's Emotional Competence}

There is a growing body of literature indicating that parents' emotion-specific parenting behaviors impact children's later social and emotional adjustment. Several studies have demonstrated that the ways in which parents react to children's displays of emotion also affect the way children cope with their own emotions. For instance, using the Coping with Children's Negative Emotion Scale (CCNES), Fabes, Poulin, Eisenberg and Madden-Dierdich (2002) examined the development of emotional competence in relation to the various methods used by parents when responding to children's negative emotion. The CCNES is a self-report scale consisting of hypothetical scenarios in which children would typically display negative emotions. Parents are asked to rate the scenarios in the manner in which they would handle the hypothetical situation using six different responses characterized by the varying emotion-specific responses to children's emotions (Fabes et al., 2002). The six categories were problem-focused responses, emotion-focused responses, expressive encouragement, minimization reactions, punitive reactions, and distress reactions. These six categories comprise the larger categories of supportive and non-supportive parenting (Fabes et al., 2002). Supportive reactions include problem-focused responses (providing solutions for regulating negative emotion), emotionfocused responses (soothing, comforting child in the face of negative emotion), and expressive encouragement (encourage expression of emotion, including negative affect). Non-supportive reactions include minimization reactions (discounting children's emotions) and punitive reactions (reprimanding a child for his/her display of emotion). Lastly, the final non-supportive reaction on the CCNES subscale is distress reactions, (parents expression of distress in the face of children's negative emotion). These six categories which create the larger scale of what is 
believed to make up both supportive and non-supportive parental reactions to children's displays of emotions have been examined in related studies of children's social and emotional development.

In a series of studies conducted by Eisenberg, Fabes, and colleagues, they investigated the socialization of emotion in young children using the CCNES as an assessment of emotion socialization. In one study, Fabes et al. (2002) examined parental reactions to children's emotions in a sample of 36 preschool-aged children and their mothers. Fabes et al. (2002) hypothesized that children reared by parents who demonstrated a supportive approach or reaction to their children's displays of negative emotion would have children who were more emotionally competent when compared to children reared by parents who responded in a non-supportive or distressing manner. Fabes et al. (2002) examined emotion socialization via the CCNES (described above) and children's emotional understanding and emotional expressiveness during a laboratory task. When comparing supportive emotional responses, Fabes et al. (2002) predicted a stronger correlation between emotion-focused responses than problem-focused responses and children's subsequent understanding and interpretation of emotions. It was found that parents who took a supportive approach when reacting to their children's displays of negative emotion had children who were better able to interpret or decode the emotions of other individuals in a hypothetical situation (Fabes et al., 2002). In addition, children whose parents showed distress when their children displayed negative emotions were incapable of decoding emotions exhibited by others (Fabes et al., 2002). In contrast, minimization or punitive reactions from parents were associated with low levels of emotional expressiveness in children during the laboratory task (Fabes et al., 2002). Thus, it appears that parental reactions to children's negative emotions were associated with the emotional well being of children. Children of parents who took a supportive 
approach when responding to their children's emotions were found to have high levels of observed emotional expressiveness, generally enhancing their emotional competence. On the contrary, children of parents who utilized unsupportive tactics when responding to their children's negative emotion were found to be rather emotionally unexpressive and may even demonstrate signs of emotional dysregulation (Fabes et al., 2002). Parents who responded to their children's emotions in a supportive manner (e.g., problem-solving) were most likely to demonstrate superior emotional development, while children reared in households in which parents took an unsupportive approach (e.g., punishment) when reacting to their children's displays of negative emotion were less skilled in their emotional development. Therefore, the manner in which parents respond to their children's displays of negative emotionality is associated with subsequent child outcomes.

In a related study, Eisenberg and Fabes (1994) studied the relation between mothers' reactions to their children's displays of negative emotions while taking into account the individual child's temperament, and the child's ability to regulate emotions in a social setting (i.e., school) (Eisenberg \& Fabes, 1994). Several predictions were made when creating the hypotheses. First, the authors hypothesized that a positive relation would exist between supportive reactions as rated by the CCNES and children's adaptive regulatory skills (Eisenberg \& Fabes, 1994). On the other hand, Eisenberg and Fabes (1994) hypothesized a positive correlation between mother's use of minimization, distress or punitive strategies (rated by the CCNES) and children's unproductive means to deal with emotional aggression.

In addition to the previously listed hypotheses, Eisenberg and Fabes (1994) made several other predications in regard to maternal reactions to children's negative emotions and child temperament. First, it was hypothesized that mothers whose children displayed high levels of 
negative affect and showed difficulty self-regulating would be less likely to encourage their children's emotional expressiveness when addressing their negative emotional displays. Further, it was predicted that mothers who provided their children with comfort, and strategies to cope with their negative emotions would have children capable of self-regulation (Eisenberg \& Fabes, 1994).

Participants included 79 four-, five-, and six-year-olds. Participants were selected based on the completion of emotion socialization questionnaires previously distributed at their preschool centers. Information was collected from mothers, teachers, and teacher aides throughout two academic semesters. In order to assess maternal reactions to negative affect, mothers completed the Coping with Children's Negative Emotions Scale (CCNES) based on 12 hypothetical situations. In addition, mothers, teachers, and teacher aides each completed items adapted from the Affective Intensity Scale (Larsen \& Diener, 1987). Observational methods were used to assess children's emotion regulation and behavior in the school environment. During a three-month period, trained study observers were stationed at various areas within the school setting, such as the classroom or playground, and were instructed to monitor child behavior, paying close attention to negative expressions expressed in an overt manner; and children's reactions to negative emotion were separated into seven categories including verbal objection, venting, defending, physical retaliation, reengage, escape, and seeks adults.

First, correlations between the emotion socialization categories were computed, and a significant, positive relation between minimization, punishment, and distress reactions was found; further, encouragement of emotional expression was negatively related to minimization/punitive responses. In addition, expressive encouragement, problem-focused, emotion-focused socialization responses were correlated with one another (Eisenberg \& Fabes, 
1994). Given the interrelations between the factors, the scales were combined to form two larger factors of supportive and non-supportive socialization practices. Next Eisenberg \& Fabes (1994) examined whether emotion socialization practices were related to observed emotional competence in the school environment. Minimization or punitive reactions were both positively related to the use of escape as a method to control emotions of anger in the school environment. Further, supportive emotion socialization practices (e.g., comforted their children when displaying negative affect) were related to children's use of healthy means of dealing with anger, such as verbalizations (Eisenberg \& Fabes, 1994). Thus, Eisenberg and Fabes (1994) established a clear relationship between maternal reactions to children's negative emotions and children's behavior, thereby lending evidence that parent emotion socialization impacts children's socioemotional development.

Further evidence provided by this group built on the findings reported by Eisenberg and Fabes (1994). For instance, Eisenberg, Fabes and Murphy (1996) examined the relation between parents' reactions to children's negative emotions and children's social competence during middle childhood; specifically, they examined children's socially appropriate behavior, peer acceptance and constructive coping mechanisms. Data were collected from 148-elementaryaged children and their parents. To measure parents' reactions to their children's negative emotions, parents completed the Coping with Children's Negative Emotions Scale (CCNES). Further, parents and teachers completed a scale adapted from Derryberry and Rothbart's (1988) temperament measure and the Affective Intensity Scale (Larsen \& Diener, 1987) to examine children's negative emotionality. Next, children's coping styles were measured by using an adaptation of the Children's Coping with Strategies Checklist completed by mothers and teachers (Ayers, Sandler, West \& Roosa, 1996), which yields 12 subscales. Data were reduced to yield 
four coping strategies: support-seeking (e.g., ask an adult for assistance); problem-solving (e.g., think about what to do before doing anything); constructive coping (e.g., would not use aggression); and avoidant coping (e.g., tries not to think about it). Finally, children's social skills were assessed by mothers and teachers via an adapted Harter's (1979) Perceived Competence Scale for Children, completed by mothers and teachers, which included statements about children's engagement in appropriate social behaviors. Mothers and teachers also assessed their child's social acceptance via an adapted Harter (1979) scale, and answered questions about children's likeability in the peer group (e.g., number of friends).

Children also completed assessments of their social behaviors, including a laboratory assessment of prosocial behavior and self-reported social skills via the Harter (1979) measure (described above). In the laboratory session, children were exposed to the sound of a crying infant and were told they could soothe the "baby" through a baby monitor. Children were also shown how to cease the sound of the baby crying (by turning the speaker off). The child was left in the room alone, and was told they could comfort the crying infant or they could turn off the speaker. These observations were coded for comforting and angry behaviors.

Data were analyzed to examine the relations between parents' emotion socialization beliefs and children's negative emotionality, social skills, coping strategies, prosocial behavior, and popularity amongst peers. Results indicated maternal problem-focused reactions were significantly associated with maternal- and self-ratings of social skills, and maternal- and teacher-ratings of constructive coping. In addition, Eisenberg et al. (1996) reported a negative relation between minimizing reactions to children's displays and teacher-ratings of social competence (e.g., popularity \& social skills). Mothers who encouraged their children to be emotionally expressive and responded to their children's emotions in an emotion-focused or 
problem-focused manner had children who displayed high levels of comforting behavior techniques during the laboratory assessment of prosocial behavior, and this was especially true among males. Thus, Eisenberg, Fabes and Murphy's (1996) belief that children's social functioning and prosocial behaviors were associated with parental reactions to children's emotion was affirmed. Findings from this study provide support for the current thesis.

Specifically, the results provided by Eisenberg et al. (1996) via the CCNES and related measures assessing children's social functioning and coping mechanisms indicate that the manner in which parents respond to their children's displays of emotions are related to children's subsequent socio-emotional competencies.

An additional longitudinal study examining the relation between parents reactions to children's negative emotions and children's social functioning was conducted by Eisenberg, Fabes, Shepard, Guthrie, Murphy and Reiser (1999). Based on previous research (Eisenberg et al., 1994; Eisenberg et al., 1996; Gottman et al., 1997), Eisenberg and colleagues hypothesized that children's coping strategies and their social behaviors in a variety of settings (home and school) would be influenced by parental reactions to their negative emotions. Eisenberg et al. (1999) further hypothesized that children's externalizing/inappropriate problem behaviors could be predicted longitudinally by parental reactions that were punitive or non-supportive in nature.

Data were collected during five assessment periods from preschool to age twelve, with the first (preschool) and second (kindergarten) assessments combined. Eisenberg and colleagues (1999) set out to examine several transactional models via SEM analysis. First, they examined the transactional relation between parent emotion socialization and externalizing affect over three time points ( $6-8$ years of age, $8-10$ years of age, and $10-12$ years of age). At all times, parents completed the Coping with Children's Negative Emotions Scale (CCNES) as an 
assessment of emotion socialization. Parents completed the Affective Intensity Measure to examine children's emotional intensity (e.g., "This [my] child tends to get nervous, tense, or distressed easily," Larsen \& Diener, 1987) and the Positive and Negative Affect Schedule (PANAS) measuring dispositional affectivity (Watson, Clark, and Tellegen, 1988); these scales were combined to assess externalizing affect. When they examined the model they found that both punitive emotion socialization and externalizing affect were stable across all time points; moreover, they found that punitive emotion socialization was predictive of externalizing affect from the $8-10$ time-point to the $10-12$ time-point.

In addition, Eisenberg and colleagues (1999) examined another transactional model, with the focus on punitive emotion socialization and regulation. Once again the CCNES was used as the index of emotion socialization, and behavioral regulation was examined via a composite of attention focusing and behavioral regulation. Attention focusing was rated by parents on a sevenpoint scale ranging from one (extremely untrue) to seven (extremely true) based on ten items adapted from Rothbart, Ahadi, and Hershey’s (1994) CBQ such as “Has difficulty leaving a project he/she has begun" (Eisenberg et al., 1999, p. 519). In addition, parents completed subscales from the CBQ assessing impulsivity, and inhibition control. Self-control was measured via items from the Self-Control Rating Scale completed by parents (Kendall \& Wilcox, 1979).

Once again, Eisenberg et al. (1999) reported that punitive emotion socialization and behavioral regulation were stable across time. Further, it appeared that punitive reactions were negatively associated with regulation longitudinally (from $8-10$ years to $10-12$ years); thus supporting the original hypothesis. In addition, it was found that low levels of children's social functioning were associated with parental reactions to children's negative emotions. Eisenberg et al. (1999) also found that parental punitive/distress reactions and children's regulatory abilities 
were somewhat predictive of children's problem behaviors, as reported by mothers at ages ten through twelve. Hence, parents who responded to their children's displays of emotionality with punitive or distress reactions predicted children's subsequent behavior problems during ages ten through twelve. In addition, children whose parents used punitive or distress reactions when reacting to their negative emotions during ages six through eight predicted children's abilities to regulate emotion during ages eight through ten (Eisenberg et al., 1999). Likewise, parental punitive reactions during ages ten through twelve were predicted by children's ability to regulate emotion during age eight through ten (Eisenberg et al., 1999). Thus, parents who take a nonsupportive approach when reacting to their children's negative emotions were found to be influential when examining children's externalized negative emotion. Interestingly, it was also found that while unsupportive parental reactions to children's negative emotions decreased during early/mid-school years, they tended to increase during late childhood and into early adolescence (Eisenberg et al., 1999). Overall, findings from this study demonstrate the way parental emotion socialization impacts children's social functioning beyond the early childhood years. Based on these findings, it is evident that when examining children's socioemotional development, researchers must take into account not only the general way that parents parent, but parental perceptions of the way they react to their children's emotionality. Specifically, the manner in which parents perceive their responses to their children's displays of negative affect were found to be predicative of children's latter social functioning. Findings from this study not only build on previous studies conducted throughout this literature review examining the manner in which parental emotion socialization influences children's social functioning, however, it is important to note that these factors were assessed longitudinally. Thus, providing support that these associations that take place during early childhood hold true in later years. 
Beyond the work of Eisenberg, Fabes, and colleagues, other researchers have demonstrated similar results with different measures. This is important to note due to the fact that it helps prove that regardless of the measures used, it is evident that the manner in which parents respond to their children's emotions and display emotionality is associated with children's socioemotional development and subsequent child behaviors. Thus, providing support for the proposed study. For instance, Denham, Zoller, and Couchoud (1994) examined interpersonal and intrapersonal differences in the socialization of preschoolers' emotion understanding. Specifically, in this study, Denham et al. (1994) examined maternal contributions to preschoolers' emotion understanding, specifically anger. Denham et al. (1994) hypothesized that the frequency of maternal displays of anger would hinder children's emotion understanding due to the insidious nature of the emotion. As aforementioned, direct contributions to children's emotion understanding can be made from parents who serve as emotion coaches. Children's emotion awareness can be credited to the communication between parent and child about the emotional situations that the child experiences (Denham et al., 1994). Consequently, Denham et al. (1994) hypothesized that children's social knowledge of emotions would be supported by frequent parent-child communication about emotions. In addition, Denham et al. (1994) hypothesized that parents' would model their children's emotions (e.g., if a child is displaying an emotion such as happiness, the parent is likely to react to the emotion with happiness). Likewise, Denham et al. (1994) hypothesized that certain parental reactions to children's emotions are more likely to inhibit the child's interest in emotion, such as when a parent responds to their children's anger with their own anger. Therefore, children's emotional expressiveness and emotion understanding may stem from the type of responsiveness their parents utilize (Denham et al., 1994). 
Forty-seven preschoolers participated in a longitudinal study spanning a period of 15 months during two consecutive preschool years. Mother-child assessments took place during two separate free play periods, the first being more casual than the second. During the first year, children's emotion labeling and use of emotion language were examined. For the emotionlabeling task, children identified happy, sad, angry, and afraid emotion expressions based on puppets with hand-drawn facial expressions. Next, the experimenter asked the children to select the puppet with the appropriate facial expression as instructed by the experimenter. For example, "Show me the _face" (Denham et al., 1994, p. 930). During two emotion perspective-taking tasks, children's emotion situation knowledge (i.e., children's understandings of others emotions which may be different than their own during the same emotion eliciting situation) was assessed. During the first emotion perspective-taking task, eight puppet vignettes were used to act out an emotion eliciting situation such as being given ice-cream or having a bad dream, while the experimenter provided vocal and visual cues. For example, puppet vignettes in which the emotion "afraid" is depicted, puppet body language and facial cues are stiff and rigid with the puppets'/puppeteer's mouth open while the puppeteer's voice may be "high-pitched," or "unwavering" (Denham et al., 1994). After the children watched the puppets, they labeled their emotions using the previously used hand-drawn faces (e.g., happy, sad, angry, and afraid). During the second emotion perspective-taking task, children's ability to identify others' emotions when they may be different than their own (based on maternal preliminary data collection) was measured. Instances such as mothers indicating that their son or daughter would be frightened to see a specific animal, the experimenter would then act out the puppet encountering the animal, matched with pleasant expressions, both vocal and visual. For each of the 12 vignettes used, the experimenter gave preschoolers points based on correct identification of the puppets expression. 
Next, Denham et al. (1994) examined child emotion language (explanations). During free play, the experimenter instructed mothers to speak with their preschoolers about eight photographs of infants, each depicting a different emotion. Once children and their mothers discussed the emotions on the photographs, the experimenter instructed mothers to casually express one of the emotions displayed on the photographs in effort to observe how the child responds to their emotions. This continued until the mothers expressed each of the eight expressions displayed on the photographs. The laboratory visit was videotaped and later coded for reference to internal emotion situations.

During the second year of measurement, Denham et al. (1994) aimed to examine causes of emotions. The tester used seminaturalistic interviews to determine children's ability to recognize varying emotions (happy, sad, angry, \& afraid) through play using puppets. If the child incorrectly stated the emotion of the puppet, the experimenter first corrected the child before proceeding to the next step. After the child correctly labeled the emotion displayed by the puppet, the tester then encouraged them to give explanations to why the puppet may be expressing the specific emotion. If the child had difficulty describing reasons for the puppets' emotions, the tester encouraged them to pretend the puppet was either themselves or their best friend. If difficulty still persisted, the experimenter provided the child with verbal prompts. All interviews were videotaped and coded using a taxonomy based on Stein and Jewett (1986) and Barrett and Campos (1987). Specifically, codes were defined as: "happiness caused by attaining a goal or desire, anger caused by goal blockage, sadness caused by loss, or fear caused by the likelihood of an unwanted occurrence" (Denham et al., 1994, p. 931).

Denham et al. (1994) found that emotion understanding during both ages (age during year one assessment and age during year two assessment) could be predicted by mothers' 
explanations for emotions as well as parents' positive and negative sensitivity to their children's emotions. When examining interpersonal contributors, Denham et al. (1994) found that when children displayed emotion during simulation tasks, mothers typically responded with the same emotion, if the emotion was anger or happiness. In addition, a significant relation was found between children's emotion understanding and mother's positive responsiveness to children's emotions (Denham et al., 1994). Thus, children reared by mother's who used positive responses when reacting to their emotional displays had more advanced or developed ability to understand emotions. Also, Denham et al. (1994) determined significant associations between the manner in which mothers socialized their children, such as serving as emotion coaches during both positive and negative displays of emotion, and children's emotion understanding. It was from this type of emotion socialization where children developed and enhanced their own understanding of emotions consequently contributing to their overall emotion knowledge. Thus, it is evident that both interpersonal and intrapersonal contributors serve as predictors to preschoolers' emotion understanding as supported by Denham et al. (1994), providing further justification for the proposed thesis study.

Additional work by Denham and colleagues has built on these associations, and has further illustrated the powerful role parents play in children's emotional development. For instance, Denham, Mitchell-Copeland, Strandberg, Auerbach and Blair (1997) investigated the parental emotion socialization (observed and parent-reported) as predictors of preschoolers' emotion expression, regulation, and understanding. As illustrated in the Denham et al. (1997) article, emotion competence can be defined as children's ability to "respond emotionally, yet simultaneously and strategically apply their knowledge about emotions and their expression to relationships with others, so that they can negotiate interpersonal exchanges and regulate their 
emotional experiences" (Saarni, 1985, p. 116).

Participants included 60 mothers and 49 fathers of preschool-aged children. In an attempt to measure socialization of emotional competence (expression, regulation, and expression of emotion), Denham et al. (1997) utilized parental self-report and parent-child observations during two separate family visits. Specifically, parents' reactions to their children's emotions and their own expression of emotions were obtained via home observations on two occasions - once with mother and once with father.

During the home observations, the experimenter instructed parent (either mother or father) to sit down and communicate with their children regarding four specific instances where the parent displayed positive or negative emotions in their child's presence. Next, children described four occasions when they displayed positive or negative emotions in front of their parents (Denham et al., 1997). Data were coded for the number of occurrences where the parent and child displayed specific emotions. In addition, parents' modeling emotions, and their reactions to children's emotions were coded. Parent reactions to children's emotions included, "matching (positive or negative emotions), inappropriate affective reaction (e.g., smiling when someone is hurt), hurt feelings, positive reinforcement, negative reinforcement, help/concern, looking, ignoring, or antisocial reactions (Denham et al., 1997, p. 73).

Further, Denham and colleagues (1997) asked parents (both mothers and fathers) to rate their own emotional expression via Linehan, Paul, and Egan's (1983) Parent Affect Test (PAT). The PAT was used to obtain data on the parents' emotional responses to children's behaviors (e.g., "My child acts respectful to me" or " My child gets into some things that don't belong to him/her"). Two scales are derived from this questionnaire: potential anger-provoking (PAT-a) and pleasure-provoking (PAT-p) responses. Data gathered during these visits were used to form 
composite scores of child and parent emotion behaviors, including the following: parental reactions to children's emotions; parental affective balance (percentage of happy emotion displays minus percentage of angry emotion displays); and parents' internalizing negative emotions (e.g., the display of sadness, fear/tension) (Denham et al., 1997). It is important to note that parenting data from mothers and fathers were aggregated to form the aforementioned parent emotion displays and socialization behaviors. These indices of parent emotion socialization were used as predictors of children's emotional competence.

Emotional competence was assessed via children's knowledge of emotions, how they expressed emotion, and their knowledge of situations where emotions were used. Emotional knowledge was assessed via children's verbal identification of various emotions such as happiness, fear, and sadness, then once again using nonverbal gestures as illustrated by the puppet vignettes. Using puppet vignettes, Denham et al. (1997) acted out a story where many emotions were expressed via the puppets' vocal and facial displays. After the story, children assigned the appropriate emotions to the puppets' faces specific to the different emotions they expressed during the story. The above measures were used in order to determine how successful the children were when identifying other's emotions during specific situations (Denham et al., 1997).

Emotional expressiveness and self-regulation were observed through the preschooler's interactions with others in the school environment. Preschool teachers also completed two questionnaires pertaining to the preschooler's social competence. First preschool childcare providers completed the Olson Preschool Competence Questionnaire, a measure including scales assessing Positive Peer Relations, Cooperativeness, and Empathy (Denham et al., 1997). In addition to the Olson Preschool Competence Questionnaire, teachers completed the Preschool 
Behavior Questionnaire (PBQ). The $P B Q$, a 30-item questionnaire, requires teachers to rate the frequency of aggressiveness and sadness/anxiousness exhibited by the. Scores produced by scales used in the Olson Preschool Competence Questionnaire and the combined scales used in the Preschool Behavior Questionnaire were then calculated to obtain an overall aggregate of social competence scores (Denham et al., 1997).

Consistent with previous research, Denham and colleagues reported that the way parents model emotion and level of parental emotional expressiveness/responsiveness predicts children's individual socio-emotional competencies (Denham et al., 1997). Specifically, results indicated that parents' negative reinforcement of children's emotion was negatively associated with children's emotion knowledge, while parents' expression of positive emotion was positively associated with children's emotion knowledge. Therefore, as parents negatively reinforce their children's displays of negative emotion, their child's emotion knowledge levels will decline. Likewise, as the frequency of parental expressiveness of positive emotion increases, the child's levels of emotion knowledge will increase as well. Further, Denham et al. (1997) found that children of parents who display high levels of positive affect were more likely to exhibit positive affect with peers and others in social situations (Denham et al., 1997). Similarly, parents who displayed negative affect when interacting with their children raised children who struggled with social competence within the observed preschool setting (Denham et al., 1997). In addition to the previous findings, it can be concluded that children whose parents utilized emotion coaching were more capable of understanding emotions altogether (Denham et al., 1997). The aforementioned findings help signify the importance of direct and indirect parental socialization of emotion and the influence it has on children's emotional competence across a variety of social settings. 
In another study, Denham and Kochanoff (2002) investigated the role of parental emotion socialization (both direct and indirect) in a sample of 134 three, four, and five year olds and their parents via child observations, questionnaires, and interviews in the home setting. In this study, Denham and Kochanoff (2002) used a variety of measures to assess familial contributions to preschoolers' emotion understanding and reported parents who are emotionally expressive and positively reinforce children's emotions have children that are better at identifying the feelings of others. Specifically, one-hundred-thirty-four 3-, 4-, and 5-year-old children and their parents participated. First, children were observed and interviewed in the home setting while parents completed questionnaires. A second home visit was then conducted when the participating children were 3- and 4-years old. During the home visits children were asked to reflect on previous experiences involving emotions such as sadness, happiness, fear, and anger and responses were then coded. Specifically, researchers coded children's emotions as reactions to the emotions their parents expressed including: "matching positive or negative emotions, inappropriate affective reaction, hurt feelings, positive or negative reinforcing, concern, looking, ignoring, or antisocial reactions" (Denham \& Kochanoff, 2002, p.320-321).

Questionnaires completed by parents reflected all areas of emotion socialization, including the above-described PAT (Linehan et al., 1983) and CCNES (Fabes et al., 2002); as well as the Parent Disciplinary Styles (PDS) measure (Hart, De Wolf, Woznaik, \& Burts, 1992). The $P D S$ asks parents to report in an open-ended fashion to vignettes about disciplinary situations. These data are coded to assess parents' encouragement/scaffolding of children's development of sympathy. Additionally, the Self-Expressiveness in the Family Questionnaire (SEFQ; Halberstadt, Cassidy, Stifter, Parke, \& Fox, 1995) was administered. The SEFQ examines one's expressiveness of positive and negative emotions in the family setting. In order 
to examine parental emotional expressiveness and their reaction to emotion, researchers observed families in the home setting (as described above in Denham et al., 1997).

Denham and Kochanoff (2002) used the Affect Knowledge Test (AKT) in order to assess the preschoolers understanding of emotion. Children were asked to verbally label puppets based on their faces, which reflected happiness, sadness, anger, and fear. Next, an emotion-eliciting story was told and children were asked to match the emotions to the puppet to accurately represent how the puppet would feel in the situation. During the second emotion identification task, children were asked to identify feelings of others that differ from how the children themselves would feel in a variety of situations (e.g., feel sad when receiving an ice cream cone). Responses for each task were then coded accordingly. The observational and self-report measures of emotion socialization were aggregated to form composite variables for the regression analyses, which were conducted separately for mothers and fathers. Specifically, emotion socialization practices were used to predict children's emotional competence.

Findings provided by Denham and Kochanoff (2002) illustrate the benefits of parental emotion expression and teaching children about emotions from an early age. It is also important for parents to be aware of the way they react to their children's displays of emotions. Each of these factors play a critical role in the way parents can contribute to the emotion understanding and knowledge of their preschoolers. Thus, it is clear that parental socialization of emotion including emotion modeling, emotion coaching, and parents' reactions to their children's emotion are key factors in children's understanding of emotion. Overall, these studies suggest that parents who are emotionally expressive and open about the discussion of emotion with their children starting at a young age do make significant contributions to children's emotional competence. Similarly, emotion-specific parenting practices such as emotion-focused parenting 
or problem-focused parenting are found to be supportive in nature, thus, decreasing the likelihood of behavioral and associated difficulties such as maladjustment in children. On the contrary, parents who practice emotion-specific parenting practices such as the minimization of children's displays of emotion or those who punish their children when an undesired emotion is exhibited are likely to raise children who have difficulty understanding and expressing emotion in a socially appropriate manner. The examination of emotion-specific parenting practices has made significant contributions to this realm of study. Previous findings and contributions have encouraged others to take different approaches to studying fundamental aspects of children's emotion socialization in which researchers agree that emotion-specific parenting practices do indeed impact child behavior (Denham et al., 1997; 2002; Eisenberg et al., 1996; 1999; Fabes et al., 2002).

\section{Collective Examination of Global and Emotion-Specific Parenting Practices}

From the literature review provided above, it is clear that that both general parenting styles (e.g., Baumrind \& Black, 1967) and emotion specific parenting strategies (e.g., Eisenberg et al., 1996) influence later socio-emotional development in children and adolescents. However, the vast majority of the literature has focused on either general parenting typologies or emotion specific parenting. There is emerging evidence in the emotion socialization literature that suggests that examining both the global (or general) and specific aspects of parenting provides the best understanding of child development. Specifically, O'Neal and Magai (2005) sought to examine the manner in which parents affect adolescents' behavior through general and emotion specific socialization techniques to help predict broad and specific indices of child behavior. Rather than looking at an aggregate of maternal reactions to children's emotions, O'Neal and Magai (2005) examined how parents may respond differently to adolescents' emotions as the 
emotions varied.

O’Neal and Magai (2005) hypothesized that parents would react differently to their adolescents' emotions based on the specific emotion displayed (e.g., sadness versus anger), and in turn, that their children would be able to notice the differences in their parents reactions. Participants in this study included 161 early adolescent children ages 11-14 years. O'Neal and Magai (2005) recruited adolescents from after-school programs, an assembly, and within the classroom of an urban middle school. Adolescents and their caregivers each separately completed interviews to identify emotion socialization practices; and adolescents, parents and teachers reported on adolescents' internalizing/externalizing behaviors levels of internalizing and externalizing problem behaviors among the participating adolescents.

O'Neal and Magai (2005) used the Emotion Socialization Strategies scale from the Emotions as a Child Scales (EAC) to assess emotion socialization through an interview method. Adolescents were asked to recall instances when they were sad, angry scared or ashamed, and to rate their caregivers response to those emotions on a seven point Likert scale. For example, questions included "Think of times you felt angry, what would your mother (or primary caregiver) do" (O’Neal \& Magai, 2005, p. 475). Next, children selected a response from one to seven, one being not at all like their parent, to seven being exactly like their parent. The Emotion Socialization Strategies subscale included questions from each domain of global socialization (reward, punish, neglect, override, and magnify). Definitions include "Reward (e.g., She understands why you feel sad, She hugs you), Punish (e.g., She calls you a crybaby), Neglect (e.g., She ignores you), Override (She tells you not to worry, She tells you to keep quiet), and Magnify (i.e., escalate; e.g., She gets angry with you)" (O'Neal \& Magai, 2005, p. 475). The five global socialization strategies each contain four separate subscales of emotion (sadness, fear, 
anger, and shame), which were each averaged to obtain a "global score". For example, global Punish is an average of the punish subscales including sad, anger, fear, and shame (O'Neal \& Magai, 2005).

Results provided by O'Neal and Magai (2005) indicated that the combination of both emotion-specific parenting practices and global socialization practices collectively help predict, interpret and understand varying child psychopathologies, better than relying on one specific pathway. Specifically, using regression analyses O'Neal and Magai (2005) reported that certain emotion socialization strategies were better predictors of internalizing and externalizing difficulties when examining across emotions, while other strategies were better predictors looking at the emotion-specific level. For example, O'Neal and Magai (2005) reported that reward of shame negatively predicted externalizing difficulties, while global reward (an aggregate of reward across four negative emotions) was not a significant predictor of externalizing behavior. Similarly, Magnify- Anger was a better predictor of externalizing difficulties than Magnify - Global. Thus it seems equally important to examine both global and emotion specific parenting practices when examining the development of internalizing and externalizing difficulties. Indeed, O’Neal and Magai (2005) concluded that the most comprehensive understanding of the development of psychopathology would be obtained by accounting for both emotion-specific socialization and global socialization. Thus is seems probable that by examining both general parenting practices (i.e., authoritative parenting) and emotion specific parenting practices (i.e., supportive reactions to children's fear) a better understanding of how parenting contributes to preschoolers' emotional and social development will be obtained. 


\section{The Current Study}

Therefore, the two bodies of literature described above (a) empirical investigations on how authoritative and authoritarian parenting contribute to children's development, and (b) the empirical work on how emotion socialization impacts children's development were integrated. Specifically, the relation between general parenting practices and emotion-specific socialization (parents' reactions to children's fear and to children's anger) were examined. Further, the contribution of both general and emotion-specific parenting to children's displays of fear/anxiety and hostility/aggression were examined. Specific hypotheses are outlined below.

\section{Hypotheses}

The first goal of the study was to examine the relations between general parenting practices and emotion-specific parenting practices. It was hypothesized that authoritative parenting techniques would be positively related to supportive emotion socialization practices, both supportive-fear and supportive-anger. It was also hypothesized that authoritative parenting will be negatively related to non-supportive emotion socialization practices, both non-supportive fear and non-supportive anger. These hypotheses were created based on the notion that supportive emotion-specific socialization practices (i.e., emotion-focused responses) are quite similar in nature to characteristics associated with authoritative parenting (i.e., warm and supportive of children's emotional displays). Similarly, since it is believed that authoritative parenting is related to supportive emotion-specific socialization practices, it is likely that as authoritative parenting levels increase, non-supportive reactions to children's emotions (i.e., anger and fear) would decrease.

In addition, it was expected that authoritarian parenting styles would be positively related to non-supportive emotion socialization practices, both non-supportive-fear and non-supportive- 
anger. Moreover, it was hypothesized that authoritarian parenting techniques would be negatively related to supportive emotion socialization practices, both supportive-fear and supportive anger. Similarly, these hypotheses were created due to the number of similarities shared among both authoritarian parenting techniques (i.e., demanding, rigid, non-supportive, lack of communication between the parent-child) and non-supportive parenting practices (i.e., minimization, punitive, and distress reactions). Further, it is expected that parents who rate high on scales for authoritarian parenting will rate relatively low regarding supportive emotion socialization practices (i.e., emotion-focused responses) in response to their children's displays of both fear and anger.

The second goal of the study was to examine the contribution (a) of general parenting practices (e.g., authoritative parenting), (b) emotion-specific parenting practices (e.g., nonsupportive reactions to children's display of fear), and (c) the combined effects of general parenting practices and emotion-specific parenting practices to children's displays of fear/anxiety and hostility/aggression. It was expected that non-supportive emotion specific socialization would moderate the relation between authoritarian parenting and displays of fear/anxiety and hostility/aggression in children, with the strongest relation between authoritarian parenting and fear/anxiety and hostility/aggression behavioral displays for those mothers who reported the highest levels of non-supportive emotion-specific socialization practices. It was also hypothesized that supportive emotion socialization strategies would ameliorate the association between authoritarian parenting and children's displays of fear/anxiety and hostility/aggression, with the strongest negative relation between authoritarian parenting and children's displays of fear/anxiety and hostility/aggression for those mothers who reported the highest levels of supportive emotion socialization strategies. 
In addition, predictions were made regarding the contribution of authoritative parenting and emotion-specific socialization practices. Specifically, it was expected that supportive emotion specific socialization strategies would moderate the relation between authoritative parenting and displays of fear/anxiety and hostility/aggression in children, with the strongest, negative relation between authoritative parenting and displays of fear/anxiety and hostility/aggression for those mothers who reported the lowest levels of supportive emotionspecific socialization practices. Moreover, it was hypothesized that non-supportive emotion socialization practices may have a deleterious effect on the association between authoritative parenting and children's adjustment, with the association between authoritative parenting and children's displays of fear/anxiety and hostility/aggression being positive when mothers reported non-supportive emotion socialization strategies in response to their children's negative emotions.

Importantly, separate analyses were conducted for mothers' responses to children's specific negative emotions, anger and fear. Better put, supportive-anger, supportive-fear, nonsupportive-anger, and non-supportive-fear were examined as individual moderators in each of the analyses; no specific hypotheses were offered given the paucity of research examining the socialization of specific negative emotions (see Kennedy Root \& Denham, in press). 


\section{Chapter 2}

\section{Methods}

\section{Participants}

Twenty-seven mothers (mean age $=34$ years) and their children (14 boys, 13 girls; mean age 3.5 years) participated in the study. The majority of the children $(85 \%)$ were White (7\% Black, 7\% Bi-racial); the majority (92\%) of the mothers were also White (4\% Black, 4\% Biracial). Eighty-two percent of the mothers reported being married to the target child's biological father, and all but one of the mothers had completed at least a University degree. The annual household income for $70 \%$ of the sample was above $\$ 75,000$ per year.

\section{Procedure}

Data were collected from the parents (mothers and fathers) and teachers of preschoolaged children who were participating in a larger study on children's emotional development. The larger study comprised an observational session, as well as questionnaire data collection; Questionnaire data collection always preceded the laboratory session. The questionnaire data collection is relevant to the current study, thus the laboratory session will not be described further.

A total of 27 mothers participated in the study. After mothers agreed to participate in a study on children's emotional development they were sent questionnaires in paper format or links to questionnaires to be completed online. Two mothers completed the questionnaires on paper and 25 mothers completed the questionnaires online. There were four questionnaires total used in the present study: a demographics questionnaire; a questionnaire about mothers' general parenting practices; a questionnaire about mothers' emotion socialization strategies to children's emotions; and a questionnaire about children's social behaviors. The questionnaires are 
described in detail below.

\section{Measures}

Demographics. Mothers completed a basic demographic questionnaire (Appendix A). They answered questions about children's age, race/ethnicity, mother's age, mother's race/ethnicity, father's age, father's race/ethnicity, and family income. In addition, mothers completed items regarding marital status and previous marriages.

Parenting Practices Questionnaire. Mothers completed The Parenting Practices Questionnaire (Robinson, Mandleco, Frost Olsen, \& Hart, 1995) (Appendix B), this is a 62-item questionnaire developed by Robinson et al. (1995) based on Baumrind's (1971) parenting styles and Block's (1965) Child-rearing Practices Report. Mothers were asked to rate the frequency in which they exhibit specific behaviors with their child. Responses were based on a 5-point Likert scale ranging from 1 (never) to 5 (always). The questionnaire yields three subscales, two of which are relevant to the present study: authoritarian and authoritative parenting. Of the 62 items, 27 items examine authoritative parenting (e.g., "Encourages our child to talk about the child's troubles," and "[helps] our child to understand the impact of behavior by encouraging our child to talk about the consequences of own actions")( $\alpha=.66)$. Authoritarian parenting items were examined via a 20-item scale (e.g., "Explodes in anger towards child." and "Uses physical punishment as a way of disciplining our child.” $\alpha=.69)$.

The Coping with Children's Negative Emotions Scale (CCNES). The CCNES (Fabes et al., 2002) (Appendix C) is a measure in which parents are asked to rate various reactions to their children's displays of negative emotions (an aggregate of reactions to children's displays of anger, sadness, fear, embarrassment, and disappointment) based on 12 hypothetical scenarios (e.g., "If my child receives an undesirable birthday gift from a friend and looks obviously 
disappointed, even annoyed, after opening it in the presence of the friend, I would:...”). For each hypothetical scenario depicting children's negative emotions, parents are asked to respond based on six choice responses (e.g., "Encourage my child to express his/her disappointed feelings" and, "Try to get my child to feel better by doing something fun"). For each of the six responses, parents are then asked to rate the likelihood that they would respond to the scenario in the same manner on a seven point Likert scale ranging from 1 (very unlikely) to 7 (very likely). The questionnaire was adapted by adding two questions about maternal responses to children's expression of anger and one question about maternal response to children's express of fear; these questions were developed by Rubin, Hastings and Henderson (1996).

The reactions to negative affect were then categorized into four subscales: 21 items comprised supportive anger (e.g., help my child think about ways to feel better; $\alpha=.71$ ); 10 items comprised non-supportive anger (e.g., punish child for his/her behavior; $\alpha=.63$ ); 33 items comprised supportive fear (e.g., tell child it's okay to feel anxious/fearful; $\alpha=.91$ ); and 24 items comprised non-supportive fear (e.g., minimize child's feelings of fear; $\alpha=.75$ )

Preschool Children's Social Behaviors Questionnaire - Parents. Mothers also completed the School Children's Behavior (SCB; Appendix D) questionnaire. This 90-item questionnaire contains items from several different measures, including the Social Skills Rating System (Gresham \& Elliott, 1990), the Preschool Behavior Questionnaire (Behar \& Stringfield, 1974), and Children's Moods, Fears, \& Worries (Bayer, Sanson, \& Hemphill, 2006). The following subscales were computed from the Preschool Behavior Questionnaire (Behar \& Stringfield, 1974): hostility/aggression and fear/anxiety. The hostility/aggression scale included seven items (e.g., fights with other children; $\alpha=.68$ ); and the fear/anxiety scale included eight items (e.g., appears unhappy, tearful, or distressed; $\alpha=.52$ ). 


\section{Analytic Strategy}

To address the first hypotheses regarding the relation between general parenting practices and emotion-specific parenting practices, correlation analyses were conducted. Specifically, the authoritative and authoritarian scales from the $P P Q$ were correlated with the supportive (fear and anger) and non-supportive scales (fear and anger) from the CCNES. Next, to test the hypotheses regarding the link between general parenting practices, emotion-specific parenting practices and children's social behavior, regression analyses were conducted. Specifically, eight separate regressions were conducted. First, four regressions were conducted in the prediction of hostility/aggression. The predictor variables were entered on the following steps: general parenting practices (authoritative or authoritarian parenting); emotion specific parenting practices (supportive-anger, supportive-fear, non-supportive-anger, or non-supportive-fear); and the interaction between the general parenting practice and emotion specific parenting practice entered in steps 1 and 2. An identical set of regressions were then conducted in the prediction of fear/anxiety. 


\section{Chapter 3}

\section{Results}

First, the data were examined for outliers, which revealed that one case was 3 standard deviations above the mean on non-supportive reactions to fear; thus that case was excluded from all analyses. In addition, there was one participant who did not complete the Pre-school Children's Social Behaviors Questionnaire, therefore sample means imputation was used to fill in the missing data. The means and standard deviations for all variables of interest are displayed in Table 1. In addition correlations were computed for all variables and are presented in Table 2. The first set of analyses was conducted to examine the relation between general and emotionspecific parenting practices. In order to examine the first set of hypotheses, bivariate correlations were conducted. The analyses regarding the specific hypotheses are presented below.

As depicted in Table 2, authoritative parenting was significantly and positively related to CCNES supportive-fear $(r=.42, p<.05)$ and CCNES supportive-anger $(r=.46, p<.05)$. However, authoritative parenting was not significantly associated with non-supportive-fear and non-supportive-anger. Further, authoritarian parenting was positively and significantly related to the CCNES non-supportive-fear $(r=.68, p<.01)$, and positively and non-significantly to $C C N E S$ non-supportive-anger $(r=.37, n s)$. Authoritarian parenting was also negatively related to the CCNES supportive-fear $(r=-.38, n s)$ and CCNES supportive-anger $(r=-.38, n s)$; however, these relations were not significant.

Next data were analyzed to examine the contribution of general and emotion-specific parenting practices to children's displays of fear/anxiety and hostility/anger. As described above, to examine the moderating effects of emotion-specific parenting practices (CCNES supportive and non-supportive reactions to children's displays of fear and anger) in relation to 
general parenting practices ( $P P Q$ Authoritative and $P P Q$ Authoritarian) in the prediction of children's internalizing (fear/anxiety) and externalizing (hostility/aggression) behaviors, regression analyses were computed (Tables 3 and 4). Maternal report of CCNES supportive and non-supportive reactions to children's displays of fear and anger as well as maternal reports of general parenting practices as reported in the $P P Q$ were first centered on their means prior to computing interactions. The findings are organized by hypothesis below.

Hypothesis: It was expected that supportive emotion socialization practices would moderate the relation between authoritative parenting and children's displays of hostility/aggression and fear/anxiety. The regression models pertaining to this hypothesis did not yield significant results. Specifically, the contribution of each predictor variables (authoritative parenting, supportive emotion socialization strategies, and the interaction between the two) did not account for a significant amount of the variance in the prediction of either hostility/aggression or fear/anxiety.

Hypothesis: It was expected that non-supportive emotion socialization practices would moderate the relation between authoritative parenting and children's displays of hostility/aggression and fear/anxiety. The regression models pertaining to this hypothesis did not yield significant results. Specifically, the contribution of each predictor variables (authoritative parenting, non-supportive emotion socialization strategies, and the interaction between the two) did not account for a significant amount of the variance in the prediction of either hostility/aggression or fear/anxiety.

Hypothesis: It was expected that supportive emotion socialization will moderate the relation between authoritarian parenting and children's displays of hostility/aggression and fear/anxiety. Authoritarian parenting was a significant main effect predictor of fear/anxiety 
$\left(\Delta R^{2}=.15 ; \Delta F=4.29 ; p<.05\right)$. The beta weight indicated that the relation between authoritarian parenting and fear/anxiety was negative $(\beta=-.39)$. Therefore, mothers who scored high on indices of authoritarian parenting had children who scored low on displays of fear/anxiety. This hypothesis was not supported in that supportive emotion socialization practices did not moderate the relationship between authoritarian parenting and fear/anxiety; in addition, the remaining regression models did not yield significant results.

Hypothesis: It was expected that non-supportive emotion socialization will moderate the relation between authoritarian parenting and children's displays of hostility/aggression and fear/anxiety. The interaction between authoritarian parenting and non-supportive anger was predictive of fear/anxiety at the trend level $\left(\Delta R^{2}=.12 ; \Delta F=3.70 ; p=.06\right)$. Interactions were explored following the recommendations of Cohen, Cohen, West, and Aiken (2003). Specifically, for each interaction I restructured the equation to express the regression of the dependent variable (fear/anxiety) on authoritarian parenting for high- and low-non-supportive anger. As indicated in Figure 1, the strongest relation between fear/anxiety and authoritarian parenting was for high non-supportive anger group, (simple slope $=-.76, p<.01$ ), whereas the simple slope for the low non-supportive anger group, (simple slope $=-.09, p=n s$ ), was not significantly different from zero. 


\section{Chapter 4}

\section{Discussion}

The primary purpose of this research study was to examine the relations between general parenting practices and emotion-specific parenting practices. A second goal of this study was to examine the contribution of (a) general parenting practices, (b) emotion-specific parenting practices, and (c) the combined effects of general parenting practices and emotion-specific parenting practices to ratings of children's fear/anxiety and hostility/aggression.

\section{Goal 1: Examine the relation between general and emotion-specific parenting practices.}

Findings indicated that authoritative parenting was significantly and positively related to supportive-fear and to supportive-anger, thus providing support for the original hypotheses. Previous research by Baumrind (1971) in which parenting typologies were examined suggests that parents who are high in authoritative parenting are characterized as warm, supportive, and nurturing in interactions between the parent and child. Similarly, in Fabes and colleagues (2002) work on emotion-specific socialization practices, supportive emotion socialization strategies have been characterized by the use of parental comfort, guidance, and acceptance of children's displays of emotions. Based on these characterizations, it is evident that both authoritative parenting styles and supportive emotion-specific socialization practices share a number of similarities. Thus, the findings reported herein are consistent with the literature. Indeed, it is reasonable to assume that parents who report high levels of authoritative parenting would report high levels of supportive emotion socialization practices in response to their children's displays of anger and fear.

Results also indicated that authoritarian parenting was significantly and positively related to non-supportive fear. In addition, the correlation analyses indicated that the association 
between authoritarian parenting and non-supportive anger was positive, however this association was non-significant and requires replication. Therefore, parents who were reported high levels of authoritarian parenting also reported higher levels of non-supportive emotion-specific socialization strategies in response to their children's displays of anger and fear. By nature, authoritarian parents are found to be strict, demanding, and non-nurturing of their children (Baumrind, 1971). Similarly, parents who utilize non-supportive emotion-specific socialization strategies may undermine the significance of their children's displays of emotion, or even use verbal or physical punishment in an attempt to control their children's emotional displays (Fabes et al., 2002). Overall, these parenting styles/characteristics are quite similar in nature.

Surprisingly, no significant relationships were found between authoritative parenting and indices of non-supportive-anger and non-supportive-fear, thus rejecting the suggested hypotheses of negative associations. While authoritative parenting was positively and significantly related to supportive emotion-specific socialization practices, no significant relations were found regarding the reverse hypotheses. Due to the fact that the indices of emotion-specific socialization strategies were not mutually exclusive, it is possible that authoritative parents may score high in regard to supportive emotion socialization strategies as well as high in respect to non-supportive emotion socialization techniques. Therefore it may be that parents who are authoritative report non-supportive socialization practices in certain situations; the context for the emotions expressed in the vignettes on the CCNES varied greatly, and some of the situations may have been relevant to some families, while others were not. This may have affected the responses for some of the mothers. Further, it is likely that children's histories with the expression of emotion and temperament also influence the way that mothers 
respond. These factors should be examined closer in future studies, as they likely influence the relation between general and emotion specific parenting.

Results also indicated that authoritarian parenting was negatively related to the supportive-fear and supportive-anger, however these relations were not significant. Research regarding the nature of authoritarian parenting (i.e., non-nurturing, strict, etc.) and emotionspecific socialization processes indicates almost complete opposite characteristics regarding supportive emotion socialization practices. Thus, it is reasonable that authoritarian parenting would be negatively associated to supportive emotion-socialization processes.

In addition, it is important to note that the levels of non-supportive parenting were relatively low in this sample (see Table 1). The mean for non-supportive-anger was 3.03, and the mean for non-supportive-fear was 1.54 on a 7-point sample. While the means are low, it is noted that the mean for non-supportive-anger is higher than that for non-supportive fear. It may be the case for supportive-anger that North American parents rarely support their children's displays of anger, as this emotion is typically "frowned upon" in Western culture (e.g., Siegel \& Alloy, 1990). Moreover, many of the vignettes in which anger was the target emotion depicted a child throwing a temper tantrum, a behavior that parents of preschoolers likely do not support. Indeed, it seems reasonable to conclude that by the age of 3, and upon school entry (which most of the sample was enrolled in preschool or day care), that parents expect their children to manage their anger in a more constructive fashion (e.g., Denham, 1998).

\section{Goal 2: Examine the contribution of general and emotion-specific parenting to children's displays of fear/anxiety and hostility/aggression.}

Few of the general and emotion-specific parenting practices were significant predictors of fear/anxiety and hostility/aggression as main or interaction effects. Indeed, only authoritarian 
parenting was found to be a main effect predictor of fear/anxiety; the beta weight indicated the relation between authoritarian parenting and fear/anxiety was negative, thus indicating that higher levels of authoritarian parenting beliefs were related to lower levels of fear/anxiety. Although this finding seems counterintuitive, this is actually partially supportive of some of the literature on the parents of inhibited, shy children. For instance, in a sample of boys, Park and colleagues (1997) reported that children were less likely to be inhibited and shy at 3-years if their parents were less sensitive and more negative in their interactions. Indeed it has been postulated that parents who convey to their children that their displays of inhibited, shy behavior is unacceptable in the early years of life may reduce their children's display of this behavior over time (e.g., Arcus \& McCartney, 1989; Park, Belsky, Putnam, \& Crnic, 1997).

Importantly, the association between authoritarian parenting and fear/anxiety was subsumed by an interaction effect (see Figure 1) at the trend level. In this interaction, it appears that mothers who were lowest in authoritarian and rated the highest levels of non-supportive reactions to anger had children who were rated to display the highest levels of fear/anxiety. This finding is definitely curious, especially since the same pattern was not found for non-supportive reactions to fear. However as discussed above, it may be that aspects of authoritarian parenting (e.g., directiveness) are important in curtailing the display of fear and anxiety. When those aspects of parenting are absent and parents respond to children's anger with punishment or minimization, they may be setting the stage for increased inhibited behavior and increased internalizing of emotions. Better put, parents who engage in low levels authoritarian parenting may be communicating to their children that they do not need to change their shy behavior (e.g., Park et al., 1997), however they are communicating to them that their feelings of anger are inappropriate and, if they are minimizing their children's emotions, unimportant via their non- 
supportive reactions to anger. According to Buck (1991), when feelings are experienced, but not expressed this could lead to internal dysregulation (e.g., feelings of fear/anxiety). Thus it may be that parents who punish or minimize their children's display of anger are saying, "Hold your emotions in" and are inadvertently creating a dysregulated child. When emotions are socialized in this matter and when parents are not attempting to re-direct their children's shyness, it may result in preschoolers who appear fearful and anxious. Of course, this is mere speculation and requires testing in future, preferably longitudinal, studies.

Moreover, these findings are consistent with previous literature in which non-supportive emotion socialization practices were examined. Hence, it appears that children whose parents practice non-supportive tactics are more likely to demonstrate emotional difficulties and be less skilled in their emotional development (Denham, 1998). For instance the findings reported herein support Fabes et al. (2002); recall, in this study they found that parents who utilized a non-supportive approach when responding to their children's displays of negative emotions had children whom demonstrated low emotion expressiveness (i.e., internalizing behaviors) as well as emotional dysregulation. Similar findings were reported by (Eisenberg et al., 1999). While these findings require further testing (see above), this finding may underscore the importance of examining both general and emotion-specific parenting practices in the prediction of children's behavior. Indeed, when emotion specific parenting was included as a moderator, a more precise "picture" of the relation between authoritarian parenting and fearful/anxious behaviors was captured (see Figure 1).

Importantly, in this study, the reactions to fear did not act as a moderator between general parenting practices and fear/anxiety, which is curious given that one would expect parents' socialization of fear would be related to the display of fear/anxiety. This requires further 
investigation, especially considering the small sample size. It may be that in a larger sample, or in a sample of children that have difficulty regulating fear, that this type of emotion socialization becomes relevant. It has been documented that parents of children with anxiety disorders often mute or ignore their children's emotional expressions (e.g., Suveg, Zeman, Flannery-Schoeder, \& Cassano, 2005).

As noted above, there were no other significant main or interaction effect predictors yielded from the regression models tested herein. Since the analyses were underpowered, the null findings are not surprising. Thus conclusions regarding the relations between these variables cannot be made at this time. It is evident that more work needs to be done using larger sample sizes. Previous findings have suggested that in order to gain the most comprehensive understanding of children's internalizing and externalizing behaviors, both global and emotionspecific indices of parenting must be used (O’Neal \& Magai, 2005). Similarly, existing literature suggests that relations between both global or general parenting practices and emotion-specific parenting strategies exist (O’Neal \& Magai, 2005). Hence, it seems likely that by using a larger sample size, significant relations regarding general and emotion-specific parenting strategies as predictors of children's displays of fear/anxiety or hostility/aggression would be found. Previous studies have detected the above-noted relations between general and emotion-specific parenting in samples of at least 100 - 150 participants.

\section{Limitations}

While the current study yielded some interesting findings, it is important to note that there were a number of limitations. First, the sample size was notably small, and was comprised of a very homogenous group of participants. Participants who completed questionnaires were mostly categorized as middle- to upper- class. These sample characteristics make it difficult to 
generalize findings beyond this sample. Findings produced from this sample may differ if conducted using a sample of low-income mothers for a number of reasons. First, higher SES mothers typically have higher levels of education than those from low-income families. Mothers who have college backgrounds may utilize different strategies when responding to their children's emotional displays that those of low socioeconomic status due to their education; further, mothers from high SES groups likely have more resources and support in their lives, which may result in more positive parenting (Conger \& Dogan, 2007). Mothers from lowincome households may not have the resources or knowledge on how to most effectively interact with their children. Life stressors from living in a low-income neighborhood may transfer into parent-child interactions, which may subsequently influence children's displays of fear/anxiety or hostility/aggression (Brooks-Gunn, Duncan, Kato Klebanov \& Sealand, 1993). Similarly, mothers from low-income neighborhoods may have to utilize different parenting strategies in an effort to keep their children safe (Brooks-Gunn et al., 1993); thus, these mothers may demonstrate higher levels of authoritarian parenting in regards to strict, directive mannerisms. In sum, previous research has shown differences in results from parents of middle to high SES and those from low SES (Leventhal \& Brooks-Gunn, 2002), making it important to examine these differences with a more economically diverse sample.

In addition, questionnaire respondents consisted of only mothers from the targeted sample. Therefore, it can be problematic that data were collected solely from a single informant from each family. Mothers who completed questionnaires may answer questions in a manner that they perceive to be socially desirable, thus skewing the data. Therefore, results of this study would hold more value if data were collected by a number of informants and if social desirability was measured and controlled in the analyses. 


\section{Future Directions}

Few studies have examined the relation between global indices of parenting and emotionspecific indices of parenting and their associations with child outcomes (e.g., O’Neal \& Magai, 2005). However, the majority of studies examining parenting behaviors and child outcomes are rather homogenous in regards to participant demographics and informants/respondents. It is evident that further research needs to be conducted to examine the manner in which each of these indices of parenting may collectively contribute to and help predict child outcomes such as internalizing and externalizing behavior. A first step in furthering this research could be to examine these associations and relationships with a larger and more heterogenous or culturally diverse sample.

Research in the area of child development focuses primarily on mothers as key socialization agents of children's behaviors, often neglecting the role fathers play in children's development and behavioral outcomes, however, this is often out of the researchers hands and primarily due to the lack of data provided by fathers. In recent years, many factors have provided reasons to further examine the paternal role of parenting. For example, as divorce rates increase, families are separated, often meaning that children split their time between both their mothers and their fathers, or in some cases one parent is granted sole custody (Parke, 2002). In addition, women are choosing to delay childbirth to pursue other interests such as education or career choices. In the past, women typically stayed home with their children while their husbands worked, however, today, we are beginning to see a reversal of roles. While paternal contributors to children's development have been minimally examined, the majority of examination relies strictly on observed face-to-face interactions between the father and child, ignoring the manner in which fathers indirectly impact their children's development (Parke, 2002). Parke (2002) 
cited a number of studies indicating that paternal contributions and overall involvement has increased in recent years, however there has been little emotion socialization work with fathers. While it is most often believed that mothers serve as the primary caregiver in the majority of homes, Parke (2002) found that "one out of five dual-career families with preschool children...fathers have significant childcare responsibility" especially during the hours that the mother works (Parke, 2002, p. 31). Thus, it is evident that more research needs to be conducted that examines fathers' contribution to children's developmental outcomes. Previous literature (e.g., Denham and Kochanoff, 2002) suggests that fathers may not be the best at explaining emotions to their children, thus it may be that fathers' role in children's emotional development is quite distinct from mothers' role. However, the literature does indicate that fathers appear to be important in the development of children's play and social skills (Parke, 2002). Thus, further underscoring the importance of researchers to examine the paternal role as distinct socialization agents in children's socio-emotional development.

Aside from paternal factors as socializers for children's development, this study could be taken a step further by including both quantitative and qualitative measures of assessment. For example, in addition to completing a series of questionnaires regarding children's socioemotional development, observations of parent-child interactions could be included. Similarly, it may be beneficial to have children answer questions regarding the manner in which their parent's respond to their emotional displays through hypothetical scenarios or semi-structured interviews (e.g., Denham et al., 1994). Separate from parental self-report, it may be beneficial to include preschool teachers or caregivers as participants in this study. Due to the fact that the majority of this sample included working parents, it is reasonable to believe that these preschool-aged children spend a large amount of time in the care/supervision of other individuals. Since the 
preschool years are such an important time for cognitive growth and understanding of emotion (Denham, 1998), children may be socialized in a different manner in these situations than they are in their home environment.

In addition to direct socialization agents such as parents, research has shown that siblings also directly and indirectly socialize children in a variety of ways (Dunn, 2007). Interactions between one's sibling and their parent may provide reinforcement for certain displays of emotion. In addition, children may model their emotions after the emotions that they view from their siblings during an emotionally arousing event. Further, children may discuss their emotions with their siblings or vice versa providing a context for future emotional displays.

Separate from parental demographics, it may be important to control for gender and ethnicity. Mothers and fathers may each socialize and reinforce different behaviors/emotions in their children depending on the sex of the child (Kennedy Root \& Denham, in press). For example, while it is socially acceptable that girls display more outward expressions of emotion such as crying, it is typically frowned upon when boys behave in a likely manner (for a relevant review, see Brody 2000). Mothers and fathers may comfort their female children for displaying such emotions, however, parents may respond in the opposite manner when their male children display the same emotions, providing important implications for the examination of the socialization of gender role differences. Aside from child gender differences, mothers and fathers socialize their children differently depending on their gender (i.e., paternal emotion socialization and child (male) outcomes vs. paternal emotion socialization and child (female) outcomes) (Cassano, Perry-Parrish, \& Zeman, 2007). Similarly, each of these interactions may further moderate the relation between general and emotion-specific parenting and subsequent child outcomes. 
Finally, much of the research in the realm of child development has focused on the manner in which parents negatively influence their children's development, largely ignoring the positive implications that parents may provide. For example, rather than examining the relationship between general and emotion-specific parenting and the manner in which it is related to children's fear/anxiety or hostility/aggression, it is equally important to examine positive outcomes (e.g., prosocial behavior). A number of findings have found positive associations between parenting strategies and such positive child outcomes. For example, Domitrovich and Bierman (2001) found that supportive parenting practices were positively related to levels of prosocial behavior. Similarly, a study produced by Gottman et al. (1997) found parental emotion-coaching was related to a reduction of problem behavior in children as well as higher levels of self-regulatory abilities. These findings suggest that parents can also positively influence children's socioemotional development. Hence, it is also important to explore the positive associations parents may have on children's developmental outcomes. A future step may be to examine the manner in which general and emotion-specific parenting practices are related to children's academic success, prosocial behavior, motivation, or selfregulation. Nonetheless, the manner in which parents react to their children's displays of emotions are one of the most important ways that parents can contribute to their children's emotional development (Denham, 1998).

\section{Conclusion}

In conclusion, the manner in which parents interact with and rear their children is an important area of child development to explore. In addition, the way that parents respond to their children's emotional displays is an equally important area to examine. While each of these aspects of parent emotion socialization may offer different insight into children's developmental 
outcomes, research has shown that it is important to examine these areas collectively ( $\mathrm{O}^{\prime} \mathrm{Neal} \&$ Magai, 2005). Through the examination of both general and emotion-specific parenting practices, parents, researchers, and policy makers alike are able to best understand how to promote and enhance children's emotional competencies in an attempt to achieve optimal development. 


\section{References}

Arcus, D., \& McCartney, K. (1989). When baby makes four: Family influences in the stability of behavioral inhibition. In S. J. Reznick (Ed.), Perspectives on Behavioral Inhibition (pp. 197-218). Chicago, IL: University of Chicago Press.

Asher, S. R., \& Wheeler, V. A. (1985). Children's loneliness: A comparison of rejected and neglected peer status. Journal of Consulting and Clinical Psychology, 53, 500-505.

Ayers, T. S., Sandler, I. N., West, S. G., \& Roosa, M. W. (1996). A dispositional and situational assessment of children's coping: Testing alternative models of coping. Journal of Personality, 64, 923-958.

Baumrind, D. (1971). Current patterns of parental authority. Developmental Psychology, 4(1), 1103.

Baumrind, D., \& Black, A. E. (1967). Socialization practices associated with dimensions of competence in preschool boys and girls. Child Development, 38(2), 291-327.

Barrett, K. C., \& Campos, J. J. (1987). Perspectives on emotional development: II. A functionalist approach to emotions. In J. D. Osofsky (Ed.), Handbook of infant development (555-578). New York: Wiley.

Bayer, J., Sanson, A., \& Hemphill, S. (2006a). Children's moods, fears, and worries: Development of an Early Childhood Parent Questionnaire. Journal of Emotional and Behavioral Disorders, 14(1), 41-49.

Bayer, J. K., Sanson, A. V., \& Hemphill, S. A. (2006b). Parent influences on early childhood internalizing difficulties. Journal of Applied Developmental Psychology, 27, 542-559.

Behar, L., \& Stringfield, S. (1974). A behavior rating scale for the preschool child. Developmental Psychology, 10(5), 601-610. 
Block, J. H. (1965). Child rearing practices report: A set of Q items for the description of parental socialization attitudes and values. Unpublished Manuscript, University of California, Institute of Human Development, Berkeley, CA.

Buck, R. (1991). Motivation, emotion and cognition: A developmental-interactionist view. In K. T. Strongman (Ed.), International Review of Studies on Emotion, Vol. 1. (pp. 101142). Chichester: Wiley.

Brody, L. R. (2000). The socialization of gender differences in emotional expression: Display rules, infant temperament, and differentiation. In A. H. Fischer (Ed.), Gender and emotion: Social psychological perspectives (pp.24-47). Cambridge, UK: Cambridge University Press.

Brooks-Gunn, J., Duncan, G. J., Kato Klebanov, P., \& Sealand, N. (1993). Do neighborhoods influence child and adolescent development? American Journal of Sociology, 99, 353395.

Cassano, M., Perry-Parrish, C., \& Zeman, J. (2007). Influence of gender on parental socialization of children's sadness regulation. Social Development, 16, 210-231.

Cohen, J., Cohen, P., West, S. G., \& Aiken, L. S. (2003). Applied multiple regression/correlation analysis for the behavioral sciences. Mahwah, NJ: Lawrence Erlbaum.

Coie, J. D., Dodge, K. A., Lochman, J. E., Coie, J. D., Underwood, M. K., \& Terry, R. (1993). Teacher behavior checklist. Journal of Consulting and Clinical Psychology, 61, 10531058.

Conger, R. D., Dogan, S. J. (2007). Social Class and Socialization in Families. In J. Grusec \& P. Hastings (Eds.), The handbook of socialization (309-327). New York: Guilford. 
Denham, S. A. (1998). Emotional development in young children. New York: Guilford.

Denham, S. A., \& Auerbach, S. (1995). Mother-child dialogue about preschoolers' emotions and preschoolers' emotional competence. Genetic, Social \& General Psychology Monographs, 121(3), 313-337.

Denham, S. A., Bassett, H. H., \& Wyatt, T. (2007). The socialization of emotional competence. In J. E. Grusec, P. D. Hastings, J. E. Grusec \& P. D. Hastings (Eds.), Handbook of socialization: Theory and research. (pp. 614-637). New York: Guilford.

Denham, S., \& Kochanoff, A. T. (2002). Parental contributions to preschoolers' understanding of emotion. Marriage \& Family Review, 34(3), 311-343.

Denham, S. A., Mitchell-Copeland, J., Strandberg, K., Auerbach, S., \& Blair, K. (1997). Parental contributions to preschoolers' emotional competence: Direct and indirect effects. Motivation \& Emotion, 21(1), 65-86.

Denham, S. A., Zoller, D., \& Couchoud, E. A. (1994). Socialization of preschoolers' emotion understanding. Developmental Psychology, 30(6), 928-936.

Derryberry, D., \& Rothbart, M. K. (1988). Arousal, affect, and attention as components of temperament. Journal of Personality and Social Psychology, 55(6), 958-966.

Dodge, K. A., Bates, J. E., \& Pettit, G. S. (1990). Mechanisms in the cycle of violence. Science, $250,1678-1683$.

Domitrovich, C. E., \& Bierman, K. L. (2001). Parenting practices and child social adjustment: Multiple pathways of influence. Merrill-Palmer Quarterly, 47(2), 235-263.

Dunn, J. (2007). Siblings and socialization. In J. Grusec \& P. Hastings (Eds.), The handbook of socialization (309-327). New York: Guilford. 
Eisenberg, N., Cumberland, A., \& Spinrad, T. L. (1998). Parental socialization of emotion. Psychological Inquiry, 9(4), 241-273.

Eisenberg, N., \& Fabes, R. A. (1994). Mothers' reactions to children's negative emotions: Relations to children's temperament and anger behavior. Merrill-Palmer Quarterly, 40(1), $138-156$.

Eisenberg, N., Fabes, R. A., \& Murphy, B. C. (1996). Parents' reactions to children's negative emotions: Relations to children's social competence and comforting behavior. Child Development, 67(5), 2227-2247.

Eisenberg, N., Fabes, R. A., Shepard, S. A., Guthrie, I. K., Murphy, B. C., \& Reiser, M. (1999). Parental reactions to children's negative emotions: Longitudinal relations to quality of children's social functioning. Child Development, 70(2), 513-534.

Fabes, R. A., Poulin, R. E., Eisenberg, N., \& Madden-Derdich, D. (2002). The coping with children's negative emotions scale (CCNES): Psychometric properties and relations with children's emotional competence. Marriage \& Family Review, 34(3), 285-311.

Gottman, J. M., Katz, L. F., \& Hooven, C. (1997). Meta-emotion: How families communicate emotionally. Hillsdale, NJ: Lawrence Erlbaum Associates, Inc.

Greenberger E., Josselson, R., Knerr, C., \& Knerr, B. (1974). The measurement and structure of psychosocial maturity. Journal of Youth and Adolescence, 4, 127-143.

Gresham, F. M. \& Elliott, S.N. (1990). Social Skills Rating System Manual. Circle Pines, MN: American Guidance Service.

Halberstadt, A. G., Cassidy, J., Stifter, C. A., Parke, R. D., \& Fox, N. A. (1995). Selfexpressiveness within the family context. Psychological Assessment, 7, 93-103.

Hart, C. H., DeWolf, D. M., Wozniak, P., \& Burts, D. C. (1992). Maternal and paternal 
disciplinary styles: Relations with preschoolers' playground behavioral observations and peer status. Child Development, 63, 879-892.

Harter, S. (1979). Perceived competence scale for children: Manual. Denver: University of Denver.

Harter, S. (1982). Perceived competence scale for children. Child Development, 53, 87-97.

Love, L. R., \& Kaswan, J. W. (1974). Troubled children: Their families, schools, and treatment. New York: Wiley.

Kendall, P. C., Wilcox, L. E., Kendall, P. C., \& Wilcox, L. E. S. (1979). Self-control rating scale. Journal of Consulting and Clinical Psychology, 47, 1020-1029.

Kennedy Root, A. E., \& Denham, S. A. (in press). The role of gender in the socialization of emotion: Key concepts and critical issues. Chapter to appear in A.E. Kennedy \& S.A. Denham (Eds.), New Directions for Child and Adolescent Development: Focus on Gender: Parent and Child Contributions to the Socialization of Emotional Competence. San Francisco: Jossey-Bass.

Lamborn, S. D., Mounts, N. S., Steinberg, L., \& Dornbusch, S. M. (1991). Patterns of competence and adjustment among adolescents from authoritative, authoritarian, indulgent, and neglectful families. Child Development, 62(5), 1049-1065.

Larsen, R., \& Diener, E. (1987). Affect intensity as an individual difference characteristic: A review. Journal of Research in Personality, 21(1), 1-39.

Leventhal, T., \& Brooks-Gunn, J. (2002). The neighborhoods they live in: The effects of neighborhood residence on child and adolescent outcomes. Psychological Bulletin, 126, $309-337$.

Linehan, M. M., Paul, E., \& Egan, K. J. (1983). Parent affect test. Journal of Clinical Child 
Psychology, 12(2), 161-166.

O'Neal, C. R., \& Magai, C. (2005). Do parents respond in different ways when children feel different emotions? The emotional context of parenting. Development and Psychopathology, 17(2), 467-487.

Park, S., Belsky, J., Putnam, S., \& Crnic, K. (1997). Infant emotionality, parenting and 3-year inhibition: Exploring stability and lawful discontinuity in a male sample. Developmental Psychology, 33, 218-227.

Parke, R. D. (2002). Fathers and families. In M. H. Bornstein (Ed), Handbook of Parenting: Vol 3. Being and Becoming a Parent ( $2^{\text {nd }}$ Edition $), 27-73$, Erlbaum: Mahwah, NJ.

Radloff, R. R. (1977). The CES-D Scale: A self-report depression scale for research in the general population. Applied Psychological Measurement, 1, 385-401.

Robinson, C., Mandleco, B., Frost, S., Olsen, S., \& Hart, C. (1995). Authoritative, authoritarian, and permissive parenting practices: Development of a new measure. Psychological Reports, 77(31), 819-830.

Rothbart, M., Ahadi, S., \& Hershey, K. (1994). Temperament and social behavior in childhood. Merrill-Palmer Quarterly, 40(1), 21-39.

Rubin, K. H., Hastings, P. D., \& Henderson, H. A. (1996). Mothers' Responses to Children's Emotional Reactions: An Observational Coding Scheme. Unpublished coding manual: University of Waterloo.

Saarni, C. (1985). Indirect processes in affect socialization. In M. Lewis \& C. Saarni (Eds.), The socialization of emotions (pp. 187-209). New York: Plenum.

Schaefer, E. (1965). Children's reports of parental behavior: An inventory. Child Development, $36,417-424$. 
Schludermann, E., \& Schludermann, S. (1970). Replicability of factors in children's report of parental behavior (CRPBI). Journal of Psychology, 76, 239-249.

Siegel, S., \& Alloy, L. (1990). Interpersonal perceptions and consequences of depressivesignificant other relationships: A naturalistic study of college roommates. Journal of Abnormal Psychology, 99, 361-373.

Stein, N. L., \& Jewett, J. L. (1986). A conceptual analysis of the meaning of negative emotions: Implications for a theory of development. In C. Izard \& P. Read (Eds.), Measurement of emotions in infants and young children, 2, (pp. 238-268). Cambridge: Cambridge University Press.

Suveg, C., Zeman, J., Flannery-Schroeder, E., \& Cassano, M. (2005). Emotion socialization in families of children with an anxiety disorder. Journal of Abnormal Child Psychology, 33 (2), 145-155.

Watson, D., Clark, L. A., Tellegen, A., Watson, D., Clark, L. A., \& Tellegen, A. (1988). Positive and negative affect schedule. Journal of Personality and Social Psychology, 54(6), 1063 1070.

Wehlage, G., Rutter, R., Smith, G., Lesko, N., \& Fernandez, R. (1989). Reducing the risk: Schools as communities of support. London: Falmer. 
Table 1

Means and Standard Deviations

\begin{tabular}{lccccc}
\hline Variable & $M$ & $S D$ & Min & Max & $N$ \\
\hline Authoritative Parenting & 4.10 & 0.34 & 3.22 & 4.67 & 26 \\
Authoritarian Parenting & 1.82 & 0.26 & 1.37 & 2.42 & 26 \\
Supportive Anger & 5.05 & 1.15 & 3.29 & 7.00 & 26 \\
Non-supportive Anger & 3.08 & 1.01 & 1.50 & 5.17 & 26 \\
Supportive Fear & 6.09 & 0.71 & 4.55 & 7.00 & 26 \\
Non-supportive Fear & 1.54 & 0.42 & 1.00 & 2.25 & 26 \\
Hostility/Aggression & 12.89 & 2.73 & 8.00 & 18.00 & 26 \\
Fear/Anxiety & 16.91 & 3.42 & 11.00 & 24.00 & 26 \\
\hline
\end{tabular}


Table 2

Correlations

Measure 1

34

5

6

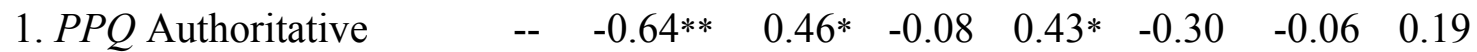

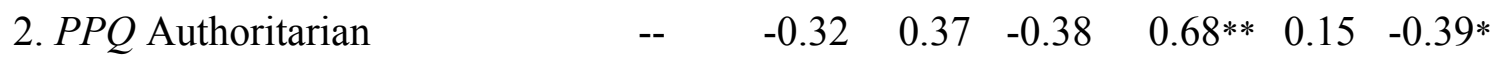

3. Supportive Anger $\quad--\quad \begin{array}{lllll}-0.34 & 0.74 * * & -0.39 & -0.21 & -0.02\end{array}$

4. Non-supportive Anger $\quad--\quad-\begin{array}{lllll}-0.19 & 0.40 * & -0.03 & 0.04\end{array}$

5. Supportive Fear $\quad--\quad \begin{array}{llll}-0.37 & -0.25 & 0.05\end{array}$

6. Non-supportive Fear

$--\quad 0.18-0.07$

7. Hostility/Aggression

$-0.19$

8. Fear/Anxiety

Note. $* p<.05 ; * * p<.01$ (2-tailed) 
Table 3

Regression analyses - Coping with Children's Negative Emotions Scale-Anger

\begin{tabular}{|c|c|c|c|c|c|c|}
\hline \multirow{2}{*}{ Predictors } & \multicolumn{3}{|c|}{$\underline{\text { Hostility/Aggression }}$} & \multicolumn{3}{|c|}{ Fear/Anxiety } \\
\hline & $\mathrm{R}$ & $\Delta \mathrm{R}^{2}$ & $\beta$ & $\mathrm{R}$ & $\Delta \mathrm{R}^{2}$ & $\beta$ \\
\hline Authoritative & 0.06 & .004 & -0.06 & 0.19 & 0.03 & 0.19 \\
\hline Supportive Anger & 0.07 & .001 & -0.04 & 0.22 & 0.01 & -0.13 \\
\hline Authoritative X Supportive Anger & 0.10 & .005 & 0.90 & 0.23 & .004 & 0.08 \\
\hline Authoritative & 0.06 & .004 & -0.06 & 0.19 & 0.03 & 0.19 \\
\hline Non-Supportive Anger & 0.21 & 0.04 & -0.22 & 0.19 & .003 & 0.06 \\
\hline Authoritative X Non-Supportive Anger & 0.27 & 0.03 & 0.17 & 0.20 & .003 & -0.07 \\
\hline Authoritarian & 0.15 & 0.02 & 0.15 & 0.40 & $0.16^{*}$ & -0.40 \\
\hline Supportive Anger & 0.23 & 0.05 & -0.19 & 0.42 & 0.02 & -0.16 \\
\hline Authoritarian X Supportive Anger & 0.25 & 0.06 & -0.10 & 0.42 & .000 & -0.01 \\
\hline Authoritarian & 0.15 & 0.02 & 0.15 & 0.39 & $0.15^{*}$ & -0.39 \\
\hline Non-Supportive Anger & 0.17 & .009 & -0.10 & 0.44 & 0.04 & 0.21 \\
\hline Authoritarian X Non-Supportive Anger & 0.21 & 0.02 & 0.13 & 0.55 & $0.12^{t}$ & -0.35 \\
\hline
\end{tabular}

Note. ${ }^{*} p<.05, t=p<.10$ 
Table 4

Regression analyses - Coping with Children's Negative Emotions Scale- Fear

Hostility/Aggression

Fear/Anxiety

Predictors

$\mathrm{R} \quad \Delta \mathrm{R}^{2}$

$\mathrm{R} \quad \Delta \mathrm{R}^{2}$

$\beta$

Authoritative

$\begin{array}{lll}0.06 & .004 & -0.06\end{array}$

$\begin{array}{lll}0.19 & 0.03 & 0.19\end{array}$

Supportive Fear

$\begin{array}{lll}0.21 & 0.04 & -0.22\end{array}$

$\begin{array}{lll}0.19 & .003 & -0.06\end{array}$

Authoritative X Supportive Fear

$\begin{array}{lll}0.27 & 0.03 & 0.17\end{array}$

$\begin{array}{lll}0.20 & .002 & 0.04\end{array}$

Authoritative

$\begin{array}{lll}0.06 & .004 & -0.06\end{array}$

$\begin{array}{lll}0.19 & 0.03 & 0.19\end{array}$

Non-Supportive Fear

$\begin{array}{lll}0.18 & 0.03 & 0.18\end{array}$

$\begin{array}{lll}0.19 \quad 000 & -0.01\end{array}$

Authoritative X Non-Supportive Fear

$\begin{array}{lll}0.35 & 0.09 & 0.31\end{array}$

$\begin{array}{lll}0.19 & .001 & 0.03\end{array}$

Authoritarian

$\begin{array}{lll}0.15 & 0.02 \quad 0.15\end{array}$

$0.40 \quad 0.15 * \quad-0.39$

Supportive Fear

$\begin{array}{lll}0.22 & 0.03 & -0.18\end{array}$

$\begin{array}{lll}0.41 & 0.02 & -0.14\end{array}$

Authoritarian X Supportive Fear

$\begin{array}{lll}0.22 & .000 & -.009\end{array}$

$\begin{array}{lll}0.41 \quad .002 & -0.04\end{array}$

Authoritarian

$\begin{array}{lll}0.15 & 0.02 & 0.15\end{array}$

$0.39 \quad 0.15 *-0.39$

Non-Supportive Fear

$\begin{array}{lll}0.18 & 0.01 \quad 0.14\end{array}$

$\begin{array}{lll}0.47 & 0.07 & 0.36\end{array}$

Authoritarian X Non-Supportive Fear

$\begin{array}{lll}0.29 & 0.05 & -0.24\end{array}$

$\begin{array}{lll}0.54 & 0.07 & -0.27\end{array}$

Note. $* p<.05, t=p<.10$ 


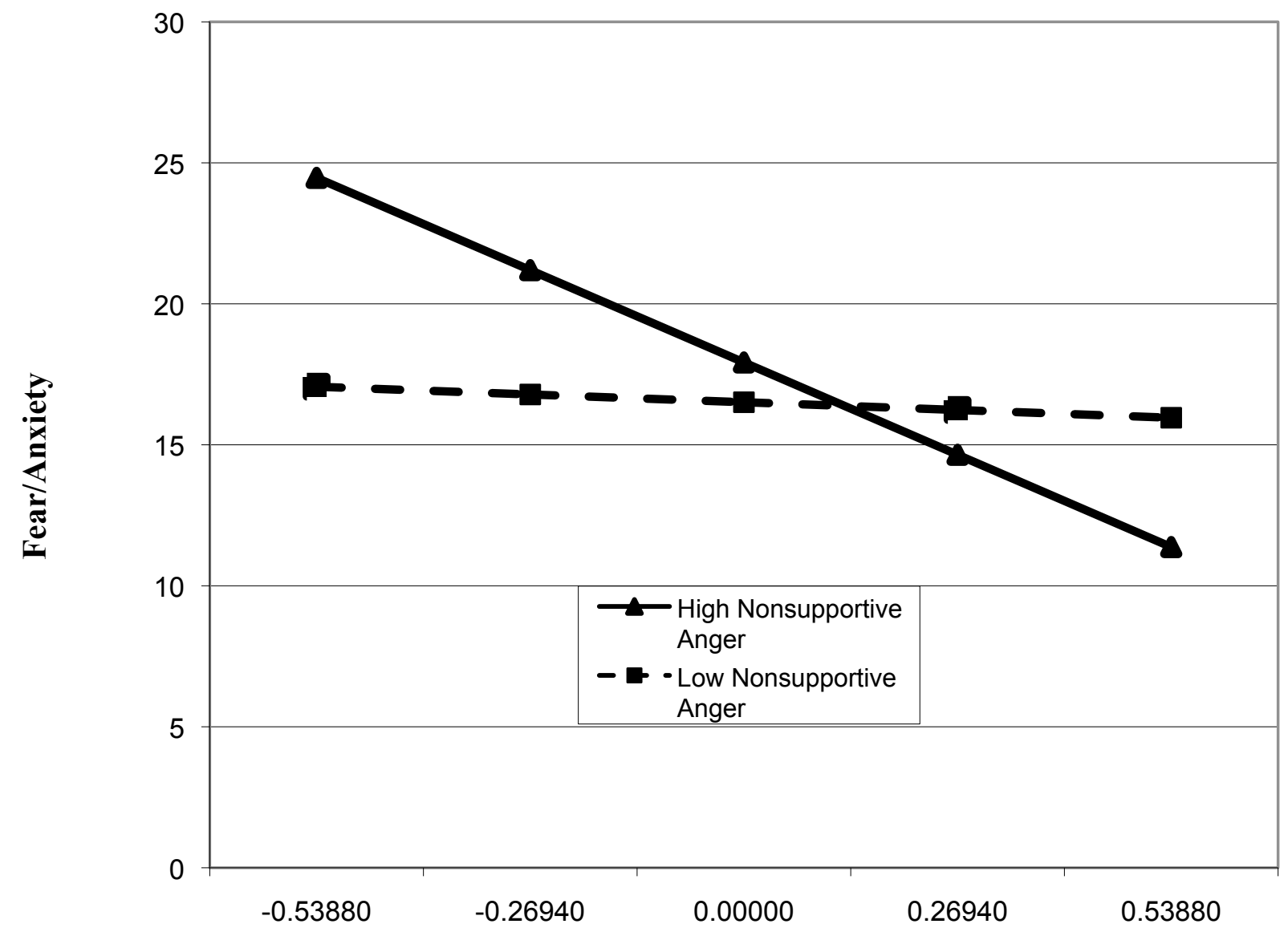

Authoritarian Parenting

Figure 1. Fear/Anxiety as a Function of Authoritarian Parenting at Levels of Non-supportive Anger 


\section{APPENDIX A}

$\underline{\text { Demographic Information }}$

Child's Birthdate

Month Day Year

Child's Age

MALE FEMALE

Child's Sex (circle one):

Child's Country of Birth

Is your child biological? Adopted? Foster child?

Child's Ethnicity (circle one):

Hispanic or Latino

Not Hispanic or Latino

\section{Child's Race (check one):}

American Indian/Alaska Native

Asian

Black or African American

Native Hawaiian or Other Pacific Islander

White or Caucasian

Bi- or Multi-racial (please specify):

Other (please specify):

Mother's Birthdate

Month Day Year

Age

\section{Occupation}

What the mother's employment status: Employed full-time

Employed part-time

Not employed outside of home

Retired

Unemployed

Other (specify)

Mother's education level:

Elementary School

High School

Vocational School

Some College

University Degree 
Some Graduate School

Master's Degree

Doctoral Degree

Other (specify)

Mother's country of birth

If mother was not born in the U.S., how long has she been residing in the U.S.?

0 to 1 year

5 to 10 years
1 to 3 years

over 10 years
3 to 5 years

Other

Mother's Ethnicity (circle one):

Hispanic or Latino

Not Hispanic or Latino

Mother's Race (check one):

American Indian/Alaska Native

Asian

Black or African American

Native Hawaiian or Other Pacific Islander

White or Caucasian

Bi- or Multi-racial (please specify):

Other (please specify):

What language is spoken most often in your home?
English
Filipino
Malaysian
Chinese
Japanese
Other (specify)

Mother's Marital Status with child's father

(check one):
Married

Separated

Divorced

Common law

Other (specify)
Spanish

Korean

Mother's current relationship status (check one):Married

Separated

Divorced

Common law

Single

Living with partner

Other (specify)

Child's Father's Birthdate

Age

Month Day Year




\section{Occupation}

What is the father's employment status: Employed full-time

Employed part-time

Not employed outside of home

Retired

Unemployed

Other (specify)

Father's education level: $\quad$ Elementary School

High School

Vocational School

Some College

University Degree

Some Graduate School

Master's Degree

Doctoral Degree

Other (specify)

Father's country of birth

If father was not born in the U.S., how long has he been residing in the U.S.?

0 to 1 year

5 to 10 years
1 to 3 years

over 10 years
3 to 5 years

Other

Father's Ethnicity (circle one):

Hispanic or Latino

Not Hispanic or Latino

Father's Race (check one):

American Indian/Alaska Native

Asian

Black or African American

Native Hawaiian or Other Pacific Islander

White or Caucasian

Bi- or Multi-racial (please specify):

Other (please specify):

Father's Marital Status with child's mother (check one):
Married Separated

Divorced

Common law

Other (specify)
How long?

How long?

How long? 
Father's current relationship status (check one): Married

Separated

Divorced

Common law

Single

Living with partner

Other (specify)

\section{Household Income:}

Less than $\$ 10,000$

$\$ 10,000$ - $\$ 25,000$

$\$ 25,000$ - $\$ 50,000$

$\$ 50,000$ - $\$ 75,000$

$\$ 75,000-\$ 100,000$

$\$ 100,000$ - \$150,000

Greater than $\$ 150,000$ 


\section{APPENDIX B}

\section{PARENTING PRACTICES QUESTIONNAIRE}

Make one rating for each item, rate how often you exhibit this behavior with your child

I Exhibit This Behavior:

$$
\begin{aligned}
& 1=\text { Never } \\
& 2=\text { Once in Awhile } \\
& 3=\text { About Half of the Time } \\
& \text { 4= Very Often } \\
& 5=\text { Always }
\end{aligned}
$$

1. I encourage my child to talk about the child's troubles.

2. I guide my child by punishment more than by reason.

3. I know the names of my child's friends.

4. I find it difficult to discipline my child.

5. I give praise when my child is good.

6. I spank when my child is disobedient.

7. I joke and play with my child.

8. I withhold scolding and / or criticism even when my child acts contrary to my wishes.

9. I show sympathy when my child is hurt or frustrated.

10. I punish by taking privileges away from my child with little if any explanation.

11. I spoil my child.

12. I give comfort and understanding when my child is upset.

13. I yell or shout when my child misbehaves.

14. I am easy going and relaxed with my child.

15. I allow my child to annoy someone else. 
16. I tell my child my expectations regarding behavior before the child engages in an activity.

17. I scold and criticize to make my child improve.

18. I show patience with my child.

19. I grab my child when being disobedient.

20. I state punishments to my child and do not actually do them.

21. I am responsive to my child's feelings or needs.

22. I allow my child to give input into family rules.

23. I argue with my child.

24. I appear confident about parenting abilities.

25. I give my child reasons why rules should be obeyed.

26. I appear to be more concerned with own feelings than with my child's feelings.

27. I tell my child that we appreciate what the child tries or accomplishes.

28. I punish by putting my child off somewhere alone with little if any explanation.

29. I help my child to understand the impact of behavior by encouraging my child to talk about the consequences of own actions.

30. I am afraid that disciplining my child for misbehavior will cause the child not to like her/ his parents.

31. I take my child's desires into account before asking the child to do something.

32. I explode in anger towards my child.

33. I am aware of problems or concerns abut my child in school.

34. I threaten my child with punishment more often than actually giving it.

35. I express affection by hugging, kissing, and holding my child. 
36. I ignore my child's misbehavior.

37. I use physical punishment as a way of disciplining my child.

38. I carry out discipline after my child misbehaves.

39. I apologize to my child when making a mistake in parenting.

40. I tell my child what to do.

41. I give in to my child when the child causes a commotion about something.

42. I talk it over and reason with my child when the child misbehaves.

43. I slap my child when the child misbehaves.

44. I disagree with my child.

45. I allow my child to interrupt others.

46. I have warm and intimate times together with my child.

47. When two children are fighting, I discipline the children first and ask questions later.

48. I encourage my child to freely express herself/himself even when disagreeing with parents.

49. I bribe my child with rewards to bring about compliance.

50. I scold or criticize when my child's behavior doesn't meet my expectation.

51. I show respect for my child's opinions by encouraging my child to express them.

52. I set strict well-established rules for my child.

53. I explain to my child how I feel about my child's good and bad behavior.

54. I use threats as punishment with little or no justification.

55. I take into account my child's preferences in making plans for the family.

56. When my child asks why s/he has to conform, I state: because I said so, or I am your parent and I want you to . 
57. I appear unsure on how to solve my child's misbehavior.

58. I explain the consequences of the child's behavior.

59. I demand that my child does things.

60. I channel my child's misbehavior into a more acceptable activity.

61. I shove my child when the child is disobedient.

62. I emphasize the reasons for rules.

63. I intervene if there is a chance that my child will fail at something.

64. I get anxious when my child tries to do something new or difficult for him/her.

65. I feel guilty when my child does not measure up to his/her potential.

66. I am fearful that others will not think well of my child.

67. I try to control much of what my child does.

68. I think it is important to supervise all of my child's activities.

69. I discourage my child from trying new things if there is a chance my child will fail.

70. I expect my child to be close by when playing.

71. I tend to be overly involved in my child's activities.

72. I tend to be overly protective with my child. 


\section{APPENDIX C \\ Coping with Children's Negative Emotions Scale}

Instructions: In the following items, please indicate on a scale from 1 (very unlikely) to 7 (very likely) the likelihood that you would respond in the ways listed for each item. Please read each item carefully and respond as honestly and sincerely as you can. For each response, please circle a number from 1-7.

$\begin{array}{lcccc}1 & 3 & 5 & 6 & 7 \\ \text { Very Unlikely } & 3 & \text { Medium } & & \\ -\end{array}$

1. If my child becomes angry because he/she is unable to go to his/her friend's birthday party, I would:

a. send my child to his/her room to cool off

1234567

b. get angry at my child

1234567

c. help my child think about ways that he/she can still be with

friends (e.g., invite some friends over after the party)

1234567

d. tell my child not to make a big deal out of missing the party

1234567

e. encourage my child to express his/her feelings of anger and frustration

1234567

f. soothe my child and do something fun with him/her to make

him/her feel better about missing the party

1234567

g. Any other reaction?

2. If my child breaks his/her new bike, and then gets upset and cries, I would:

a. remain calm and not let myself get anxious

1234567

b. comfort my child and try to get him/her to forget

about the accident

1234567

c. tell my child that he/she is over-reacting

1234567

d. help my child figure out how to get the bike fixed

1234567

e. tell my child it's OK to cry

1234567

f. tell my child to stop crying or he/she won't be

allowed to ride his/her bike anytime soon

1234567

g. Any other reaction?

\section{If my child loses some prized possession (stuffed animal) and reacts with tears, I would:}

a. get upset with him/her for being so careless and

then crying about it

b. tell my child that he/she is over-reacting

1234567

c. help my child think of places he/she hasn't looked yet

1234567

d. distract my child by talking about happy things

1234567

e. tell him/her it's OK to cry when you feel unhappy

1234567

f. tell him/her that's what happens when you're not careful

g. Any other reaction? 
4. If my child is afraid of injections and becomes quite shaky and teary while waiting for his/her turn to get a shot, I would:

a. tell him/her to shape up or he/she won't be allowed

to do something he/she likes to do (e.g., watch TV)

1234567

b. encourage my child to talk about his/her fears

1234567

c. tell my child not to make big deal of the shot

1234567

d. tell him/her not to embarrass us by crying

1234567

e. comfort him/her before and after the shot

1234567

f. talk to my child about ways to make it hurt less

(such as relaxing so it won't hurt or taking deep breaths).

1234567

g. Any other reaction?

5. If my child is going over to spend the afternoon at a friend's house and becomes nervous and upset because I can't stay there with him/her, I would:

a. distract my child by talking about all the fun he/she will have with his/her friend

1234567

b. help my child think of things that he/she could do so that

being at the friend's house without me wasn't scary

(e.g., take a favorite book or toy with him/her)

1234567

c. tell my child to quit over-reacting and being a baby

1234567

d. tell the child that if he/she doesn't stop that he/she

1234567

won't be allowed to go out anymore

1234567

e. feel upset and uncomfortable because of my child's reactions

1234567

g. Any other reaction?

6. If my child is participating in some group activity with his/her friends and proceeds to make a mistake and then looks embarrassed and on the verge of tears, I would:

a. comfort my child and try to make him/her feel better

1234567

b. tell my child that he/she is over-reacting

1234567

c. feel uncomfortable and embarrassed myself

1234567

d. tell my child to straighten up or we'll go home right away

1234567

e. encourage my child to talk about his/her feelings

of embarrassment

1234567

f. tell my child that I'll help him/her practice so that

he/she can do better next time

1234567

g. Any other reaction?

7. If my child is about to appear in a recital or sports activity and becomes visibly nervous about people watching him/her, I would:

a. help my child think of things that he/she could do to get ready for his/her turn (e.g., to do some warm-ups and not to look at the audience)

b. suggest that my child think about something relaxing

so that his/her nervousness will go away

1234567

c. remain calm and not get nervous myself

1234567

d. tell my child that he/she is being a baby about it

1234567

e. tell my child that if he/she doesn't calm down, we'll

have to leave and go home right away

1234567

f. encourage my child to talk about his/her nervous feelings

1234567

g. Any other reaction? 
8. If my child receives an undesirable birthday gift from a friend and looks obviously disappointed, even annoyed, after opening it in the presence of the friend, I would:

a. encourage my child to express his/her disappointed feelings

1234567

b. tell my child that the present can be exchanged

for something the child wants

c. NOT be annoyed with my child for being rude

1234567

1234567

d. tell my child that he/she is over-reacting

1234567

e. scold my child for being insensitive to the

friend's feelings

1234567

f. try to get my child to feel better by doing something fun

1234567

g. Any other reaction?

9. If my child is panicky and can't go to sleep after watching a scary TV show, I would:

a. encourage my child to talk about what scared him/her

1234567

b. get upset with him/her for being silly

1234567

c. tell my child that he/she is over-reacting

1234567

d. help my child think of something to do so that he/she can get

to sleep (e.g., take a toy to bed, leave the lights on)

1234567

e. tell him/her to go to bed or he/she won't be allowed to

watch any more TV

1234567

f. do something fun with my child to help him/her forget

about what scared him/her

1234567

g. Any other reaction?

10. If my child is at a park and appears on the verge of tears because the other children are mean to him/her and won't let him/her play with them, I would:

a. NOT get upset myself

1234567

b. tell my child that if he/she starts crying

then we'll have to go home right away

1234567

c. tell my child it's OK to cry when he/she feels bad

1234567

d. comfort my child and try to get him/her to think about

something happy

1234567

e. help my child think of something else to do

1234567

f. tell my child that he/she will feel better soon

1234567

g. Any other reaction?

11. If my child is playing with other children and one of them calls him/her names, and my child then begins to tremble and become tearful, I would:

a. tell my child not to make a big deal out of it

1234567

b. feel upset myself

1234567

c. tell my child to behave or we'll have to go home right away

1234567

d. help my child think of constructive things to do when

other children tease him/her (e.g., find other things to do)

1234567

e. comfort him/her and play a game to take his/her mind off

the upsetting event

1234567

f. encourage him/her to talk about how it hurts to be teased

1234567

g. Any other reaction? 
12. If my child is shy and scared around strangers and consistently becomes teary and wants to stay in his/her bedroom whenever family friends and their children come to visit, I would:

a. help my child think of things to do that would make meeting my friends less scary (e.g., to take a favorite toy with

him/her when meeting my friends)

1234567

b. tell my child that it is OK to feel nervous

1234567

c. try to make my child happy by talking about the fun

things we can do with our friends

1234567

d. feel upset and uncomfortable because of my child's reactions

1234567

e. tell my child that he/she must stay in the living room

and visit with our friends

1234567

f. tell my child that he/she is being a baby

1234567

g. Any other reaction?

13. It is $\mathbf{1 5}$ minutes until dinner is ready. Your child asks for a cookie because she/he is "starving." You explain that dinner will be ready in 15 minutes and that she/he will have to wait until then. Your child yells and stomps his or her feet continuously. I would:

a. punish him/her for his/her behavior

1234567

b. get angry for his/her overreaction

1234567

c. tell my child that he/she is over-reacting

1234567

d. help my child think of something to do so that he/she can get

keep occupied until dinner

1234567

e. tell my child that it's o.k. to feel angry, but s/he will have to wait for dinner

1234567

f. comfort my child by offering an alternate healthy snack (e.g., carrots)

1234567

g. Any other reaction?

14. You and your child are in a toy store. Your child asks you to buy him/her a new toy. You tell your child no, that she/he just received several new toys at her/his birthday party, and then you go to leave the store. Your child throws her/himself onto the floor kicking and screaming, yelling that she/he wants the toy. Your child will not leave the store. I would:

a. NOT get upset myself

b. tell my child that if he/she will be punished when you get home

1234567

c. tell my child it's OK to be anger, but they need to calm down

1234567

d. comfort my child and suggest to him/her how to calm down

(e.g., count to five; deep breaths)

1234567

e. distract my child by reminding him/her of another fun activity

s/he'll be doing later in the day/week

1234567

f. tell my child to stop acting like a baby

1234567

g. Any other reaction?

15. You've moved into a new neighborhood, and your child is invited to a birthday party being held for the child next door. You take your child to the party and stay awhile. You notice that your child looks very nervous and uncomfortable, and is keeping to her/himself.

a. tell my child not to make a big deal out of it

b. feel upset myself and uncomfortable because of my child's reactions

1234567

c. tell my child that s/he must remain at the party

1234567

d. help my child think of constructive things to do to feel more comfortable

1234567

e. tell my child s/he is being a baby

1234567

f. tell my child it's OK to be nervous

1234567

g. Any other reaction? 
16. Your child has a race with friends in the neighborhood, comes in first, and is very excited. When you get home, for a long time, your child continues to jump around gleefully and exclaim to you about her/his victory.

a. praise my child for his/her accomplishment, encourage him/her to celebrate

1234567

b. tell my child that it is OK to feel happy

c. point out my child's accomplishment, and tell him/her I am proud of him/her

1234567

1234567

d. feel uncomfortable because of my child's jubilant behavior

1234567

e. tell my child that it's not that big of a deal, and to calm down

1234567

f. tell my child to calm down or they'll get a time out

1234567

g. Any other reaction?

17. It is your sister's birthday and she has invited the whole family to celebrate by going out for dinner. The restaurant she has chosen is rather elegant and formal. During the dinner your child exuberantly jumps out of his/her chair and shouts, "Happy birthday, Auntie!"
a. Encourage him/her to celebrate
1234567
b. tell my child that it is OK to feel happy
1234567
c. point out that my child's reaction was thoughtful, and tell him/her I am proud of him/her
1234567
d. feel uncomfortable because of my child's jubilant behavior
1234567
e. tell my child to calm down
1234567
f. tell my child to calm down or they won't get any birthday cake
1234567

g. Any other reaction? 


\section{APPENDIX D}

\section{PRE-SCHOOL CHILDREN'S BEHAVIOR QUESTIONNAIRE}

This questionnaire consists of a series of descriptions of behavior often shown by preschoolers. For each statement, please circle the number which best describes this child's recent and current behaviour (within the past 6 months). Please try to answer every item. If you really can't answer an item, circle "Don't know". Try not to spend too much time on any one question.

\begin{tabular}{c}
$\begin{array}{c}\text { Almost } \\
\text { never }\end{array}$ \\
Rarely Sometimes Often $\begin{array}{c}\text { Almost } \\
\text { always }\end{array} \quad \begin{array}{c}\text { Don't } \\
\text { know }\end{array}$ \\
\hline
\end{tabular}

1. Restless - runs about or jumps up and down, doesn’t keep still.

2. Squirmy, fidgety child.

3. Destroys own or other's belongings.

4. Fights with other children.

5. Not much liked by other children.

6. Worries about things.

7. Tends to do things on his/her own, is rather solitary.

8. Irritable, quick to "fly off the handle".

9. Appears miserable, unhappy, tearful, or distressed.

10. Has twitches, mannerisms, or tics of his/her face.

11. Bites nails or fingers.

12. Is disobedient.

13. Can't concentrate or attend for long.

14. Tends to be fearful or afraid of new things or new situations.

15. Fussy, wants things to be "just right", or "perfect".

16. Tells lies.

17. Is kind, loving with other children.

18. Is withdrawn with other children.

19. Shares toys, belongings with other children.

20. Bullies other children.

\section{1}

1

1

1

\section{1}

1

1

1

1

1

1

\section{1}

1

12

12

12

12

12

1

\begin{tabular}{|c|c|c|}
\hline \multicolumn{3}{|c|}{$\begin{array}{l}\text { ONNAIRE } \\
\text { n by preschoolers. For each } \\
\text { ad current behaviour (within } \\
\text { swer an item, circle "Don't }\end{array}$} \\
\hline metimes & Often & $\begin{array}{l}\text { Almos } \\
\text { always }\end{array}$ \\
\hline 3 & 4 & 5 \\
\hline 3 & 4 & 5 \\
\hline 3 & 4 & 5 \\
\hline 3 & 4 & 5 \\
\hline 3 & 4 & 5 \\
\hline 3 & 4 & 5 \\
\hline 3 & 4 & 5 \\
\hline 3 & 4 & 5 \\
\hline 3 & 4 & 5 \\
\hline 3 & 4 & 5 \\
\hline 3 & 4 & 5 \\
\hline 3 & 4 & 5 \\
\hline 3 & 4 & 5 \\
\hline 3 & 4 & 5 \\
\hline 3 & 4 & 5 \\
\hline & & \\
\hline
\end{tabular}

\begin{tabular}{|c|c|c|}
\hline \multicolumn{3}{|c|}{$\begin{array}{l}\text { ONNAIRE } \\
\text { n by preschoolers. For each } \\
\text { ad current behaviour (within } \\
\text { swer an item, circle "Don't }\end{array}$} \\
\hline metimes & Often & $\begin{array}{l}\text { Almos } \\
\text { always }\end{array}$ \\
\hline 3 & 4 & 5 \\
\hline 3 & 4 & 5 \\
\hline 3 & 4 & 5 \\
\hline 3 & 4 & 5 \\
\hline 3 & 4 & 5 \\
\hline 3 & 4 & 5 \\
\hline 3 & 4 & 5 \\
\hline 3 & 4 & 5 \\
\hline 3 & 4 & 5 \\
\hline 3 & 4 & 5 \\
\hline 3 & 4 & 5 \\
\hline 3 & 4 & 5 \\
\hline 3 & 4 & 5 \\
\hline 3 & 4 & 5 \\
\hline 3 & 4 & 5 \\
\hline & & \\
\hline
\end{tabular}

\begin{tabular}{|c|c|c|}
\hline \multicolumn{3}{|c|}{$\begin{array}{l}\text { ONNAIRE } \\
\text { n by preschoolers. For each } \\
\text { ad current behaviour (within } \\
\text { swer an item, circle "Don't }\end{array}$} \\
\hline metimes & Often & $\begin{array}{l}\text { Almos } \\
\text { always }\end{array}$ \\
\hline 3 & 4 & 5 \\
\hline 3 & 4 & 5 \\
\hline 3 & 4 & 5 \\
\hline 3 & 4 & 5 \\
\hline 3 & 4 & 5 \\
\hline 3 & 4 & 5 \\
\hline 3 & 4 & 5 \\
\hline 3 & 4 & 5 \\
\hline 3 & 4 & 5 \\
\hline 3 & 4 & 5 \\
\hline 3 & 4 & 5 \\
\hline 3 & 4 & 5 \\
\hline 3 & 4 & 5 \\
\hline 3 & 4 & 5 \\
\hline 3 & 4 & 5 \\
\hline & & \\
\hline
\end{tabular}

\begin{tabular}{|c|c|c|}
\hline \multicolumn{3}{|c|}{$\begin{array}{l}\text { ONNAIRE } \\
\text { n by preschoolers. For each } \\
\text { ad current behaviour (within } \\
\text { swer an item, circle "Don't }\end{array}$} \\
\hline metimes & Often & $\begin{array}{l}\text { Almos } \\
\text { always }\end{array}$ \\
\hline 3 & 4 & 5 \\
\hline 3 & 4 & 5 \\
\hline 3 & 4 & 5 \\
\hline 3 & 4 & 5 \\
\hline 3 & 4 & 5 \\
\hline 3 & 4 & 5 \\
\hline 3 & 4 & 5 \\
\hline 3 & 4 & 5 \\
\hline 3 & 4 & 5 \\
\hline 3 & 4 & 5 \\
\hline 3 & 4 & 5 \\
\hline 3 & 4 & 5 \\
\hline 3 & 4 & 5 \\
\hline 3 & 4 & 5 \\
\hline 3 & 4 & 5 \\
\hline & & \\
\hline
\end{tabular}

\begin{tabular}{|c|c|c|}
\hline \multicolumn{3}{|c|}{$\begin{array}{l}\text { ONNAIRE } \\
\text { n by preschoolers. For each } \\
\text { ad current behaviour (within } \\
\text { swer an item, circle "Don't }\end{array}$} \\
\hline metimes & Often & $\begin{array}{l}\text { Almos } \\
\text { always }\end{array}$ \\
\hline 3 & 4 & 5 \\
\hline 3 & 4 & 5 \\
\hline 3 & 4 & 5 \\
\hline 3 & 4 & 5 \\
\hline 3 & 4 & 5 \\
\hline 3 & 4 & 5 \\
\hline 3 & 4 & 5 \\
\hline 3 & 4 & 5 \\
\hline 3 & 4 & 5 \\
\hline 3 & 4 & 5 \\
\hline 3 & 4 & 5 \\
\hline 3 & 4 & 5 \\
\hline 3 & 4 & 5 \\
\hline 3 & 4 & 5 \\
\hline 3 & 4 & 5 \\
\hline & & \\
\hline
\end{tabular}

\begin{tabular}{|c|c|c|}
\hline \multicolumn{3}{|c|}{$\begin{array}{l}\text { ONNAIRE } \\
\text { n by preschoolers. For each } \\
\text { ad current behaviour (within } \\
\text { swer an item, circle "Don't }\end{array}$} \\
\hline metimes & Often & $\begin{array}{l}\text { Almos } \\
\text { always }\end{array}$ \\
\hline 3 & 4 & 5 \\
\hline 3 & 4 & 5 \\
\hline 3 & 4 & 5 \\
\hline 3 & 4 & 5 \\
\hline 3 & 4 & 5 \\
\hline 3 & 4 & 5 \\
\hline 3 & 4 & 5 \\
\hline 3 & 4 & 5 \\
\hline 3 & 4 & 5 \\
\hline 3 & 4 & 5 \\
\hline 3 & 4 & 5 \\
\hline 3 & 4 & 5 \\
\hline 3 & 4 & 5 \\
\hline 3 & 4 & 5 \\
\hline 3 & 4 & 5 \\
\hline & & \\
\hline
\end{tabular}

\begin{tabular}{|c|c|c|}
\hline \multicolumn{3}{|c|}{$\begin{array}{l}\text { ONNAIRE } \\
\text { n by preschoolers. For each } \\
\text { ad current behaviour (within } \\
\text { swer an item, circle "Don't }\end{array}$} \\
\hline metimes & Often & $\begin{array}{l}\text { Almos } \\
\text { always }\end{array}$ \\
\hline 3 & 4 & 5 \\
\hline 3 & 4 & 5 \\
\hline 3 & 4 & 5 \\
\hline 3 & 4 & 5 \\
\hline 3 & 4 & 5 \\
\hline 3 & 4 & 5 \\
\hline 3 & 4 & 5 \\
\hline 3 & 4 & 5 \\
\hline 3 & 4 & 5 \\
\hline 3 & 4 & 5 \\
\hline 3 & 4 & 5 \\
\hline 3 & 4 & 5 \\
\hline 3 & 4 & 5 \\
\hline 3 & 4 & 5 \\
\hline 3 & 4 & 5 \\
\hline & & \\
\hline
\end{tabular}

\begin{tabular}{|c|c|c|}
\hline \multicolumn{3}{|c|}{$\begin{array}{l}\text { ONNAIRE } \\
\text { n by preschoolers. For each } \\
\text { ad current behaviour (within } \\
\text { swer an item, circle "Don't }\end{array}$} \\
\hline metimes & Often & $\begin{array}{l}\text { Almos } \\
\text { always }\end{array}$ \\
\hline 3 & 4 & 5 \\
\hline 3 & 4 & 5 \\
\hline 3 & 4 & 5 \\
\hline 3 & 4 & 5 \\
\hline 3 & 4 & 5 \\
\hline 3 & 4 & 5 \\
\hline 3 & 4 & 5 \\
\hline 3 & 4 & 5 \\
\hline 3 & 4 & 5 \\
\hline 3 & 4 & 5 \\
\hline 3 & 4 & 5 \\
\hline 3 & 4 & 5 \\
\hline 3 & 4 & 5 \\
\hline 3 & 4 & 5 \\
\hline 3 & 4 & 5 \\
\hline & & \\
\hline
\end{tabular}

4

\begin{tabular}{|c|c|c|}
\hline \multicolumn{3}{|c|}{$\begin{array}{l}\text { ONNAIRE } \\
\text { n by preschoolers. For each } \\
\text { ad current behaviour (within } \\
\text { swer an item, circle "Don't }\end{array}$} \\
\hline metimes & Often & $\begin{array}{l}\text { Almos } \\
\text { always }\end{array}$ \\
\hline 3 & 4 & 5 \\
\hline 3 & 4 & 5 \\
\hline 3 & 4 & 5 \\
\hline 3 & 4 & 5 \\
\hline 3 & 4 & 5 \\
\hline 3 & 4 & 5 \\
\hline 3 & 4 & 5 \\
\hline 3 & 4 & 5 \\
\hline 3 & 4 & 5 \\
\hline 3 & 4 & 5 \\
\hline 3 & 4 & 5 \\
\hline 3 & 4 & 5 \\
\hline 3 & 4 & 5 \\
\hline 3 & 4 & 5 \\
\hline 3 & 4 & 5 \\
\hline & & \\
\hline
\end{tabular}

\begin{tabular}{|c|c|c|}
\hline \multicolumn{3}{|c|}{$\begin{array}{l}\text { ONNAIRE } \\
\text { n by preschoolers. For each } \\
\text { ad current behaviour (within } \\
\text { swer an item, circle "Don't }\end{array}$} \\
\hline metimes & Often & $\begin{array}{l}\text { Almos } \\
\text { always }\end{array}$ \\
\hline 3 & 4 & 5 \\
\hline 3 & 4 & 5 \\
\hline 3 & 4 & 5 \\
\hline 3 & 4 & 5 \\
\hline 3 & 4 & 5 \\
\hline 3 & 4 & 5 \\
\hline 3 & 4 & 5 \\
\hline 3 & 4 & 5 \\
\hline 3 & 4 & 5 \\
\hline 3 & 4 & 5 \\
\hline 3 & 4 & 5 \\
\hline 3 & 4 & 5 \\
\hline 3 & 4 & 5 \\
\hline 3 & 4 & 5 \\
\hline 3 & 4 & 5 \\
\hline & & \\
\hline
\end{tabular}

\begin{tabular}{|c|c|c|}
\hline \multicolumn{3}{|c|}{$\begin{array}{l}\text { ONNAIRE } \\
\text { n by preschoolers. For each } \\
\text { ad current behaviour (within } \\
\text { swer an item, circle "Don't }\end{array}$} \\
\hline metimes & Often & $\begin{array}{l}\text { Almos } \\
\text { always }\end{array}$ \\
\hline 3 & 4 & 5 \\
\hline 3 & 4 & 5 \\
\hline 3 & 4 & 5 \\
\hline 3 & 4 & 5 \\
\hline 3 & 4 & 5 \\
\hline 3 & 4 & 5 \\
\hline 3 & 4 & 5 \\
\hline 3 & 4 & 5 \\
\hline 3 & 4 & 5 \\
\hline 3 & 4 & 5 \\
\hline 3 & 4 & 5 \\
\hline 3 & 4 & 5 \\
\hline 3 & 4 & 5 \\
\hline 3 & 4 & 5 \\
\hline 3 & 4 & 5 \\
\hline & & \\
\hline
\end{tabular}

\begin{tabular}{|c|c|c|}
\hline \multicolumn{3}{|c|}{$\begin{array}{l}\text { ONNAIRE } \\
\text { n by preschoolers. For each } \\
\text { ad current behaviour (within } \\
\text { swer an item, circle "Don't }\end{array}$} \\
\hline metimes & Often & $\begin{array}{l}\text { Almos } \\
\text { always }\end{array}$ \\
\hline 3 & 4 & 5 \\
\hline 3 & 4 & 5 \\
\hline 3 & 4 & 5 \\
\hline 3 & 4 & 5 \\
\hline 3 & 4 & 5 \\
\hline 3 & 4 & 5 \\
\hline 3 & 4 & 5 \\
\hline 3 & 4 & 5 \\
\hline 3 & 4 & 5 \\
\hline 3 & 4 & 5 \\
\hline 3 & 4 & 5 \\
\hline 3 & 4 & 5 \\
\hline 3 & 4 & 5 \\
\hline 3 & 4 & 5 \\
\hline 3 & 4 & 5 \\
\hline & & \\
\hline
\end{tabular}

\begin{tabular}{|c|c|c|}
\hline \multicolumn{3}{|c|}{$\begin{array}{l}\text { ONNAIRE } \\
\text { n by preschoolers. For each } \\
\text { ad current behaviour (within } \\
\text { swer an item, circle "Don't }\end{array}$} \\
\hline metimes & Often & $\begin{array}{l}\text { Almos } \\
\text { always }\end{array}$ \\
\hline 3 & 4 & 5 \\
\hline 3 & 4 & 5 \\
\hline 3 & 4 & 5 \\
\hline 3 & 4 & 5 \\
\hline 3 & 4 & 5 \\
\hline 3 & 4 & 5 \\
\hline 3 & 4 & 5 \\
\hline 3 & 4 & 5 \\
\hline 3 & 4 & 5 \\
\hline 3 & 4 & 5 \\
\hline 3 & 4 & 5 \\
\hline 3 & 4 & 5 \\
\hline 3 & 4 & 5 \\
\hline 3 & 4 & 5 \\
\hline 3 & 4 & 5 \\
\hline & & \\
\hline
\end{tabular}

\begin{tabular}{|c|c|c|}
\hline \multicolumn{3}{|c|}{$\begin{array}{l}\text { ONNAIRE } \\
\text { n by preschoolers. For each } \\
\text { ad current behaviour (within } \\
\text { swer an item, circle "Don't }\end{array}$} \\
\hline metimes & Often & $\begin{array}{l}\text { Almos } \\
\text { always }\end{array}$ \\
\hline 3 & 4 & 5 \\
\hline 3 & 4 & 5 \\
\hline 3 & 4 & 5 \\
\hline 3 & 4 & 5 \\
\hline 3 & 4 & 5 \\
\hline 3 & 4 & 5 \\
\hline 3 & 4 & 5 \\
\hline 3 & 4 & 5 \\
\hline 3 & 4 & 5 \\
\hline 3 & 4 & 5 \\
\hline 3 & 4 & 5 \\
\hline 3 & 4 & 5 \\
\hline 3 & 4 & 5 \\
\hline 3 & 4 & 5 \\
\hline 3 & 4 & 5 \\
\hline & & \\
\hline
\end{tabular}

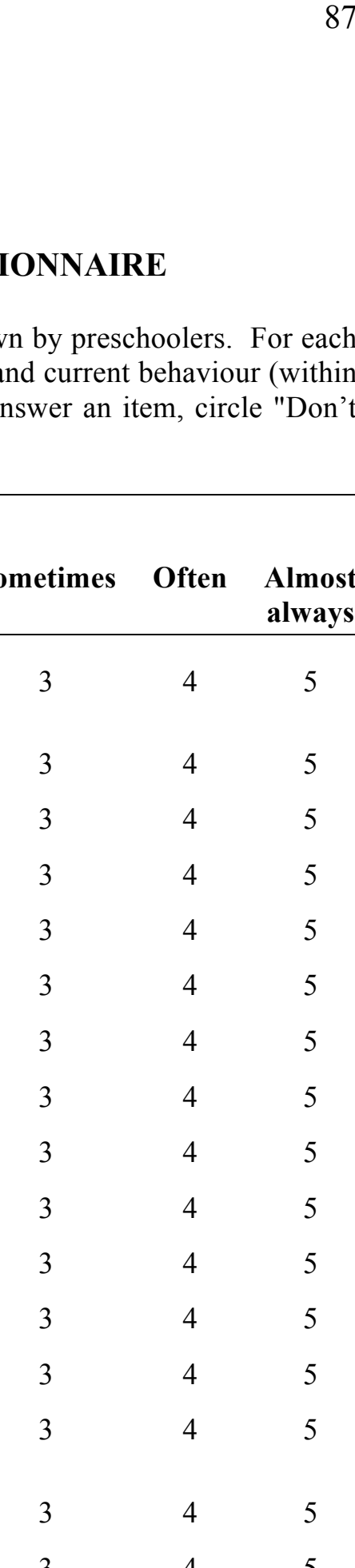

\begin{tabular}{|c|c|c|}
\hline \multicolumn{3}{|c|}{$\begin{array}{l}\text { ONNAIRE } \\
\text { n by preschoolers. For each } \\
\text { nd current behaviour (within } \\
\text { aswer an item, circle "Don' }\end{array}$} \\
\hline metimes & Often & $\begin{array}{l}\text { Almos } \\
\text { always }\end{array}$ \\
\hline 3 & 4 & 5 \\
\hline 3 & 4 & 5 \\
\hline 3 & 4 & 5 \\
\hline 3 & 4 & 5 \\
\hline 3 & 4 & 5 \\
\hline 3 & 4 & 5 \\
\hline 3 & 4 & 5 \\
\hline 3 & 4 & 5 \\
\hline 3 & 4 & 5 \\
\hline 3 & 4 & 5 \\
\hline 3 & 4 & 5 \\
\hline 3 & 4 & 5 \\
\hline 3 & 4 & 5 \\
\hline 3 & 4 & 5 \\
\hline 3 & 4 & 5 \\
\hline & & \\
\hline
\end{tabular}

\begin{tabular}{|c|c|c|}
\hline \multicolumn{3}{|c|}{$\begin{array}{l}\text { ONNAIRE } \\
\text { n by preschoolers. For each } \\
\text { ad current behaviour (within } \\
\text { swer an item, circle "Don't }\end{array}$} \\
\hline metimes & Often & $\begin{array}{l}\text { Almos } \\
\text { always }\end{array}$ \\
\hline 3 & 4 & 5 \\
\hline 3 & 4 & 5 \\
\hline 3 & 4 & 5 \\
\hline 3 & 4 & 5 \\
\hline 3 & 4 & 5 \\
\hline 3 & 4 & 5 \\
\hline 3 & 4 & 5 \\
\hline 3 & 4 & 5 \\
\hline 3 & 4 & 5 \\
\hline 3 & 4 & 5 \\
\hline 3 & 4 & 5 \\
\hline 3 & 4 & 5 \\
\hline 3 & 4 & 5 \\
\hline 3 & 4 & 5 \\
\hline 3 & 4 & 5 \\
\hline & & \\
\hline
\end{tabular}

\begin{tabular}{|c|c|c|}
\hline \multicolumn{3}{|c|}{$\begin{array}{l}\text { ONNAIRE } \\
\text { n by preschoolers. For each } \\
\text { ad current behaviour (within } \\
\text { swer an item, circle "Don't }\end{array}$} \\
\hline metimes & Often & $\begin{array}{l}\text { Almos } \\
\text { always }\end{array}$ \\
\hline 3 & 4 & 5 \\
\hline 3 & 4 & 5 \\
\hline 3 & 4 & 5 \\
\hline 3 & 4 & 5 \\
\hline 3 & 4 & 5 \\
\hline 3 & 4 & 5 \\
\hline 3 & 4 & 5 \\
\hline 3 & 4 & 5 \\
\hline 3 & 4 & 5 \\
\hline 3 & 4 & 5 \\
\hline 3 & 4 & 5 \\
\hline 3 & 4 & 5 \\
\hline 3 & 4 & 5 \\
\hline 3 & 4 & 5 \\
\hline 3 & 4 & 5 \\
\hline & & \\
\hline
\end{tabular}

\begin{tabular}{|c|c|c|}
\hline \multicolumn{3}{|c|}{$\begin{array}{l}\text { ONNAIRE } \\
\text { n by preschoolers. For each } \\
\text { ad current behaviour (within } \\
\text { swer an item, circle "Don't }\end{array}$} \\
\hline metimes & Often & $\begin{array}{l}\text { Almos } \\
\text { always }\end{array}$ \\
\hline 3 & 4 & 5 \\
\hline 3 & 4 & 5 \\
\hline 3 & 4 & 5 \\
\hline 3 & 4 & 5 \\
\hline 3 & 4 & 5 \\
\hline 3 & 4 & 5 \\
\hline 3 & 4 & 5 \\
\hline 3 & 4 & 5 \\
\hline 3 & 4 & 5 \\
\hline 3 & 4 & 5 \\
\hline 3 & 4 & 5 \\
\hline 3 & 4 & 5 \\
\hline 3 & 4 & 5 \\
\hline 3 & 4 & 5 \\
\hline 3 & 4 & 5 \\
\hline & & \\
\hline
\end{tabular}

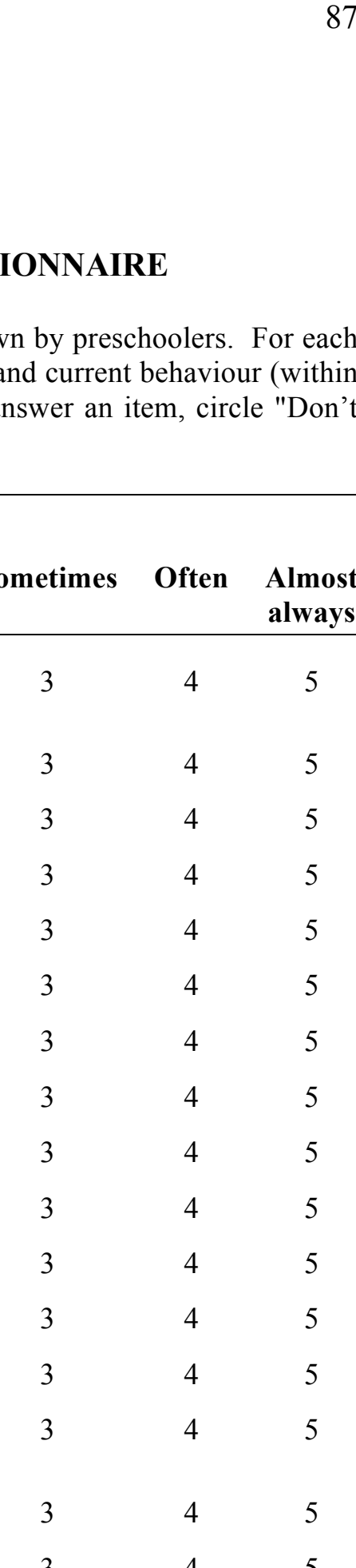

\begin{tabular}{|c|c|c|}
\hline \multicolumn{3}{|c|}{$\begin{array}{l}\text { ONNAIRE } \\
\text { n by preschoolers. For each } \\
\text { nd current behaviour (within } \\
\text { aswer an item, circle "Don' }\end{array}$} \\
\hline metimes & Often & $\begin{array}{l}\text { Almos } \\
\text { always }\end{array}$ \\
\hline 3 & 4 & 5 \\
\hline 3 & 4 & 5 \\
\hline 3 & 4 & 5 \\
\hline 3 & 4 & 5 \\
\hline 3 & 4 & 5 \\
\hline 3 & 4 & 5 \\
\hline 3 & 4 & 5 \\
\hline 3 & 4 & 5 \\
\hline 3 & 4 & 5 \\
\hline 3 & 4 & 5 \\
\hline 3 & 4 & 5 \\
\hline 3 & 4 & 5 \\
\hline 3 & 4 & 5 \\
\hline 3 & 4 & 5 \\
\hline 3 & 4 & 5 \\
\hline & & \\
\hline
\end{tabular}

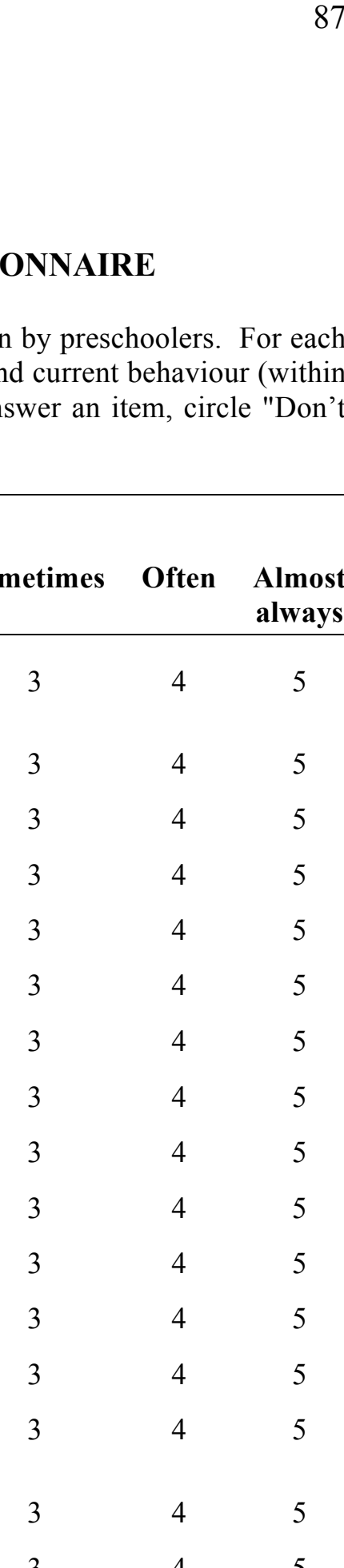

\begin{tabular}{|c|c|c|}
\hline \multicolumn{3}{|c|}{$\begin{array}{l}\text { ONNAIRE } \\
\text { n by preschoolers. For each } \\
\text { ad current behaviour (within } \\
\text { swer an item, circle "Don't }\end{array}$} \\
\hline metimes & Often & $\begin{array}{l}\text { Almos } \\
\text { always }\end{array}$ \\
\hline 3 & 4 & 5 \\
\hline 3 & 4 & 5 \\
\hline 3 & 4 & 5 \\
\hline 3 & 4 & 5 \\
\hline 3 & 4 & 5 \\
\hline 3 & 4 & 5 \\
\hline 3 & 4 & 5 \\
\hline 3 & 4 & 5 \\
\hline 3 & 4 & 5 \\
\hline 3 & 4 & 5 \\
\hline 3 & 4 & 5 \\
\hline 3 & 4 & 5 \\
\hline 3 & 4 & 5 \\
\hline 3 & 4 & 5 \\
\hline 3 & 4 & 5 \\
\hline & & \\
\hline
\end{tabular}

\begin{tabular}{|c|c|c|}
\hline \multicolumn{3}{|c|}{$\begin{array}{l}\text { ONNAIRE } \\
\text { n by preschoolers. For each } \\
\text { ad current behaviour (within } \\
\text { swer an item, circle "Don't }\end{array}$} \\
\hline metimes & Often & $\begin{array}{l}\text { Almos } \\
\text { always }\end{array}$ \\
\hline 3 & 4 & 5 \\
\hline 3 & 4 & 5 \\
\hline 3 & 4 & 5 \\
\hline 3 & 4 & 5 \\
\hline 3 & 4 & 5 \\
\hline 3 & 4 & 5 \\
\hline 3 & 4 & 5 \\
\hline 3 & 4 & 5 \\
\hline 3 & 4 & 5 \\
\hline 3 & 4 & 5 \\
\hline 3 & 4 & 5 \\
\hline 3 & 4 & 5 \\
\hline 3 & 4 & 5 \\
\hline 3 & 4 & 5 \\
\hline 3 & 4 & 5 \\
\hline & & \\
\hline
\end{tabular}

\begin{tabular}{|c|c|c|}
\hline \multicolumn{3}{|c|}{$\begin{array}{l}\text { ONNAIRE } \\
\text { n by preschoolers. For each } \\
\text { ad current behaviour (within } \\
\text { swer an item, circle "Don't }\end{array}$} \\
\hline metimes & Often & $\begin{array}{l}\text { Almos } \\
\text { always }\end{array}$ \\
\hline 3 & 4 & 5 \\
\hline 3 & 4 & 5 \\
\hline 3 & 4 & 5 \\
\hline 3 & 4 & 5 \\
\hline 3 & 4 & 5 \\
\hline 3 & 4 & 5 \\
\hline 3 & 4 & 5 \\
\hline 3 & 4 & 5 \\
\hline 3 & 4 & 5 \\
\hline 3 & 4 & 5 \\
\hline 3 & 4 & 5 \\
\hline 3 & 4 & 5 \\
\hline 3 & 4 & 5 \\
\hline 3 & 4 & 5 \\
\hline 3 & 4 & 5 \\
\hline & & \\
\hline
\end{tabular}

\begin{tabular}{|c|c|c|}
\hline \multicolumn{3}{|c|}{$\begin{array}{l}\text { ONNAIRE } \\
\text { n by preschoolers. For each } \\
\text { ad current behaviour (within } \\
\text { swer an item, circle "Don't }\end{array}$} \\
\hline metimes & Often & $\begin{array}{l}\text { Almos } \\
\text { always }\end{array}$ \\
\hline 3 & 4 & 5 \\
\hline 3 & 4 & 5 \\
\hline 3 & 4 & 5 \\
\hline 3 & 4 & 5 \\
\hline 3 & 4 & 5 \\
\hline 3 & 4 & 5 \\
\hline 3 & 4 & 5 \\
\hline 3 & 4 & 5 \\
\hline 3 & 4 & 5 \\
\hline 3 & 4 & 5 \\
\hline 3 & 4 & 5 \\
\hline 3 & 4 & 5 \\
\hline 3 & 4 & 5 \\
\hline 3 & 4 & 5 \\
\hline 3 & 4 & 5 \\
\hline & & \\
\hline
\end{tabular}

\begin{tabular}{|c|c|c|}
\hline \multicolumn{3}{|c|}{$\begin{array}{l}\text { ONNAIRE } \\
\text { n by preschoolers. For each } \\
\text { ad current behaviour (within } \\
\text { swer an item, circle "Don't }\end{array}$} \\
\hline metimes & Often & $\begin{array}{l}\text { Almos } \\
\text { always }\end{array}$ \\
\hline 3 & 4 & 5 \\
\hline 3 & 4 & 5 \\
\hline 3 & 4 & 5 \\
\hline 3 & 4 & 5 \\
\hline 3 & 4 & 5 \\
\hline 3 & 4 & 5 \\
\hline 3 & 4 & 5 \\
\hline 3 & 4 & 5 \\
\hline 3 & 4 & 5 \\
\hline 3 & 4 & 5 \\
\hline 3 & 4 & 5 \\
\hline 3 & 4 & 5 \\
\hline 3 & 4 & 5 \\
\hline 3 & 4 & 5 \\
\hline 3 & 4 & 5 \\
\hline & & \\
\hline
\end{tabular}

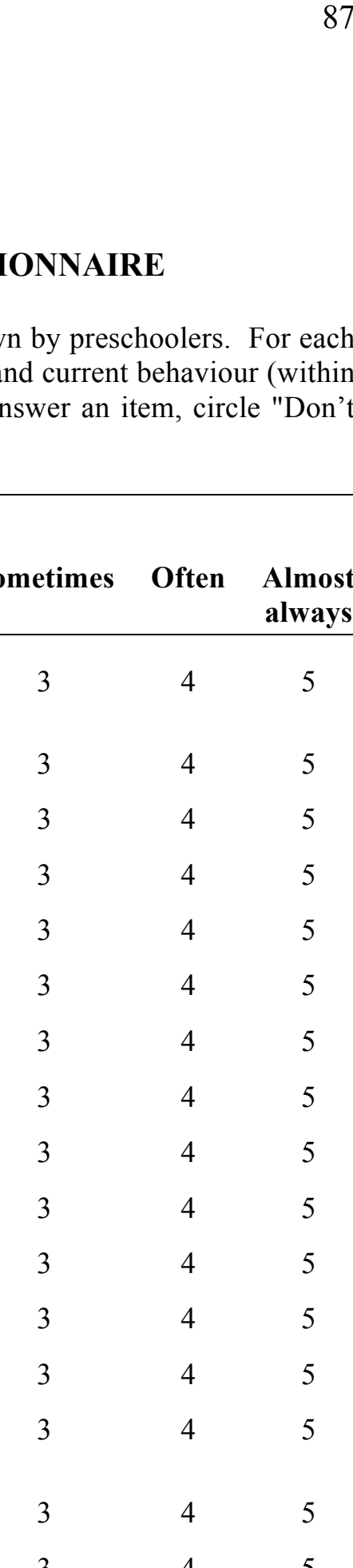

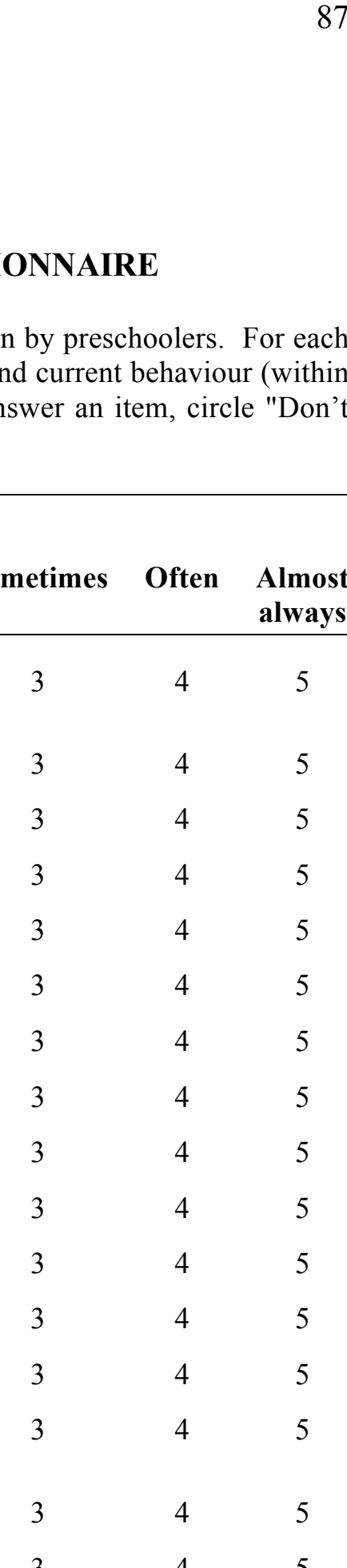

\begin{tabular}{|c|c|c|}
\hline \multicolumn{3}{|c|}{$\begin{array}{l}\text { ONNAIRE } \\
\text { n by preschoolers. For each } \\
\text { ad current behaviour (within } \\
\text { swer an item, circle "Don't }\end{array}$} \\
\hline metimes & Often & $\begin{array}{l}\text { Almos } \\
\text { always }\end{array}$ \\
\hline 3 & 4 & 5 \\
\hline 3 & 4 & 5 \\
\hline 3 & 4 & 5 \\
\hline 3 & 4 & 5 \\
\hline 3 & 4 & 5 \\
\hline 3 & 4 & 5 \\
\hline 3 & 4 & 5 \\
\hline 3 & 4 & 5 \\
\hline 3 & 4 & 5 \\
\hline 3 & 4 & 5 \\
\hline 3 & 4 & 5 \\
\hline 3 & 4 & 5 \\
\hline 3 & 4 & 5 \\
\hline 3 & 4 & 5 \\
\hline 3 & 4 & 5 \\
\hline & & \\
\hline
\end{tabular}

\begin{tabular}{|c|c|c|c|}
\hline \multicolumn{4}{|c|}{$\begin{array}{l}\text { ONNAIRE } \\
\text { n by preschoolers. For each } \\
\text { ad current behaviour (within } \\
\text { swer an item, circle "Don't }\end{array}$} \\
\hline metimes & Often & $\begin{array}{l}\text { Almost } \\
\text { always }\end{array}$ & $\begin{array}{l}\text { Don't } \\
\text { know }\end{array}$ \\
\hline 3 & 4 & 5 & 6 \\
\hline 3 & 4 & 5 & 6 \\
\hline 3 & 4 & 5 & 6 \\
\hline 3 & 4 & 5 & 6 \\
\hline 3 & 4 & 5 & 6 \\
\hline 3 & 4 & 5 & 6 \\
\hline 3 & 4 & 5 & 6 \\
\hline 3 & 4 & 5 & 6 \\
\hline 3 & 4 & 5 & 6 \\
\hline 3 & 4 & 5 & 6 \\
\hline 3 & 4 & 5 & 6 \\
\hline 3 & 4 & 5 & 6 \\
\hline 3 & 4 & 5 & 6 \\
\hline 3 & 4 & 5 & 6 \\
\hline 3 & 4 & 5 & 6 \\
\hline 3 & 4 & 5 & 6 \\
\hline 3 & 4 & 5 & 6 \\
\hline 3 & 4 & 5 & 6 \\
\hline 3 & 4 & 5 & 6 \\
\hline 3 & 4 & 5 & 6 \\
\hline
\end{tabular}

3




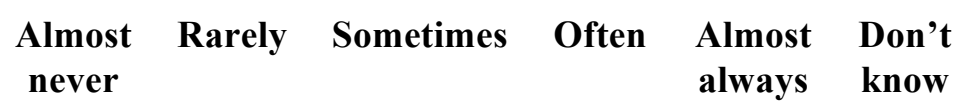

21. Inattentive, doesn't notice what is happening.

22. Doesn't share toys.

23. Cries easily.

24. Blames others.

25. Gives up easily.

26. Does not consider the feelings of others.

27. Imaginative, creative.

28. Kicks, bites, or hits children.

29. Stares into space.

30. Has temper tantrums.

31. Disturbs others' ongoing activities (eg. another child's play).

32. Says nobody likes him or her.

33. Is aggressive toward people or objects.

34. Shows anxiety about being with a group of children.

35. Follows your instructions.

36. Attempts household tasks before asking for your help

37. Attends to your instructions.

38. Prefers to play alone than with other children.

39. Puts away toys or other household property (either with or without being asked).

40. Receives criticism well.

41. Follows household rules.

42. Is disturbed by change.

43. Has fun, displays peak positive affect.

44. Likes to go out (e.g., play dates).

45. When out, eager to return home quickly.

46. Is affectionate.

47. Is anxious.

\section{1}

12

1

1

\section{1}

1

1

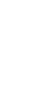

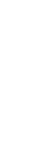

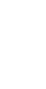

.

1

\section{1}

1

.


48. Responds positively to affection from others.

$\begin{array}{llll}3 & 4 & 5 & 6 \\ 3 & 4 & 5 & 6 \\ 3 & 4 & 5 & 6 \\ 3 & 4 & 5 & 6 \\ 3 & 4 & 5 & 6 \\ 3 & 4 & 5 & 6 \\ 3 & 4 & 5 & 6\end{array}$

49. Refuses active games.

50. Cries for long periods.

51. Is slow-moving.

52. Is moody.

53. Looks tense (e.g., furrowed eyebrows/forehead).

54. Speaks to people (in addition to family) when outside the home.

55. Resists sleeping alone.

56. Has difficulty falling asleep.

57. Wakes up during the night (e.g., bad dreams).

58. Shows interest in his/her surroundings.

59. Has irritable or cranky moods.

60. Gets upset over little things.

61. Shows significant changes in his/her appetite for food.

62. Whines.

63. Has easily hurt feelings.

64. Is unsure, indecisive.

65. Avoids eye contact.

66. Whimpers.

67. Clings to adults.

68. Gets distracted, has a short attention span.

69. Watches other children play rather than join in.

70. Seems nervous (e.g., foot-tapping, nail-biting, hairpulling).

71. Sucks his/her thumb or finger (when awake).

72. Is easily disappointed.

73. Seems lonely.

74. Trembles.

75. Displays fear of: medical procedures (injections, throat swabs). going to child care/kindergarten.

1
1
1
1
1
1
1

1

2

2

2

2

2

2

2

$$
4
$$$$
4
$$

12

12

12

12

12

12

$\begin{array}{ll}1 & 2 \\ 1 & 2\end{array}$

12

12

12

12

1

2

2

1
1
1
1

2

2

2

2

3

$\begin{array}{ll}1 & 2 \\ 1 & 2\end{array}$

$\begin{array}{llll}3 & 4 & 5 & 6 \\ 3 & 4 & 5 & 6\end{array}$


animals.

heights.

surprise toys (jack-in-the-box, masks).

illness, dirt or germs.

loved ones dying.

going to the toilet.

imaginary creatures (e.g., ghosts, monsters).

strangers.

the dark.

separation from parents.

being alone.

loud noises (e.g., trains, thunder, vacuum cleaners).

other (describe)

$\begin{array}{llllll}1 & 2 & 3 & 4 & 5 & 6 \\ 1 & 2 & 3 & 4 & 5 & 6 \\ 1 & 2 & 3 & 4 & 5 & 6 \\ 1 & 2 & 3 & 4 & 5 & 6 \\ 1 & 2 & 3 & 4 & 5 & 6 \\ 1 & 2 & 3 & 4 & 5 & 6 \\ 1 & 2 & 3 & 4 & 5 & 6 \\ 1 & 2 & 3 & 4 & 5 & 6 \\ 1 & 2 & 3 & 4 & 5 & 6 \\ 1 & 2 & 3 & 4 & 5 & 6 \\ 1 & 2 & 3 & 4 & 5 & 6 \\ 1 & 2 & 3 & 4 & 5 & 6 \\ 1 & 2 & 3 & 4 & 5 & 6 \\ 1 & 2 & 3 & 4 & 5 & 6\end{array}$

76. Has physical complaints:

aches, pains.

dizziness, headaches, "funny head".

nausea, vomiting, stomach aches, "funny tummy".

frequent urination or diarrhoea.

intermittent cold or eczema.

77. Looks guilty about his/her behaviour.

78. Seems to feel unloved.

79. Is self-conscious.

80. Makes friends easily.

81. Looks embarrassed.

82. Looks ashamed.

83. Describes others as "mean".

84. Tries hard to be "good" and well-mannered.

85 . Is insecure.

86. Worries about making mistakes.

$\begin{array}{llllll}1 & 2 & 3 & 4 & 5 & 6 \\ 1 & 2 & 3 & 4 & 5 & 6 \\ 1 & 2 & 3 & 4 & 5 & 6 \\ 1 & 2 & 3 & 4 & 5 & 6 \\ 1 & 2 & 3 & 4 & 5 & 6 \\ 1 & 2 & 3 & 4 & 5 & 6 \\ 1 & 2 & 3 & 4 & 5 & 6 \\ 1 & 2 & 3 & 4 & 5 & 6 \\ 1 & 2 & 3 & 4 & 5 & 6 \\ 1 & 2 & 3 & 4 & 5 & 6 \\ 1 & 2 & 3 & 4 & 5 & 6 \\ 1 & 2 & 3 & 4 & 5 & 6 \\ 1 & 2 & 3 & 4 & 5 & 6 \\ 1 & 2 & 3 & 4 & 5 & 6 \\ 1 & 2 & 3 & 4 & 5 & 6\end{array}$




\begin{tabular}{cccccc}
$\begin{array}{c}\text { Almost } \\
\text { never }\end{array}$ & Rarely & Sometimes & Often & $\begin{array}{c}\text { Almost } \\
\text { always }\end{array}$ & $\begin{array}{c}\text { Don't } \\
\text { know }\end{array}$ \\
\hline 1 & 2 & 3 & 4 & 5 & 6 \\
1 & 2 & 3 & 4 & 5 & 6 \\
1 & 2 & 3 & 4 & 5 & 6 \\
\hline
\end{tabular}

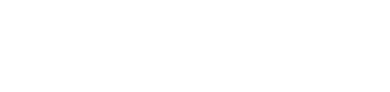

Hagen 